\title{
Una evaluación de las oportunidades humanas en El Salvador*
}

URI: http://hdl.handle.net/11298/281

\author{
Pablo Amaya ${ }^{1}$ \\ Investigador \\ pamaya01@hotmail.com \\ Recibido: 02/09/16 - Aceptado: 29/09/16
}

*Este documento es un producto del Programa Cohesión Territorial para el Desarrollo, coordinado por RimispCentro Latinoamericano para el Desarrollo Rural e implementado con socios en ocho países de la región, con financiamiento del International Development Research Centre (IDRC, Canadá).

\section{Resumen}

La desigualdad en El Salvador se ha convertido en un componente inherente a la sociedad, en un mal estructural que se acepta y condiciona las oportunidades de los niños, las cuales están fuertemente influenciadas por el territorio donde habitan.

En este trabajo se realizaron dos estimaciones del índice de Oportunidades Humanas ( $\mathrm{IOH})$. La primera destinada a evidenciar la inequitativa distribución de las oportunidades en los territorios, a desnudar aquellas regiones con urgencia de intervención y propiciar su reorientación; la segunda, que develó los factores explicativos de las discrepancias del IOH en el espacio, por medio del uso de la descomposición de Shorrocks-Shapley de 1999, evaluando su evolución en el tiempo.

A pesar de que se observan avances territoriales importantes en términos del $\mathrm{IOH}$, todavía se conservan algunos patrones regionales significativos. La franja central de El Salvador, identificada por el corredor de las principales ciudades, Santa Ana, San Salvador y la parte norte de La Libertad y San Miguel, evidencian tener mejores oportunidades de desarrollo que el resto del país. Las franjas norte y sur poseen territorios rezagados con niveles de $\mathrm{IOH}$ en el

\section{Abstract}

Inequality in El Salvador has become an inherent component to society, a structural ailment that is accepted and which conditions opportunities for children-- who are strongly influenced by the place they live in.

Two estimates on the Human Opportunities Index $(\mathrm{IOH}$, given its Spanish acronym) were conducted during this research. The first one was designated to evidence the unequal opportunity distribution in territories, to strip those regions which urgently need to be intervened and thus foster their reorientation. The second one unveiled the explanatory factors of the $\mathrm{IOH}$ discrepancies in said place by using Shorrocks-Shapley inequality decomposition by factor components (1999), hence evaluating its evolution in time. In spite of the territorial advances that were observed in terms of the $\mathrm{IOH}$, some significant regional patterns persist. The central fringes of El Salvador, identified by the main corridors of the principal cities, Santa Ana, San Salvador, the northern part of San Miguel and La Libertad, prove to have better opportunities for development than the rest of the country. The northern and southern fringes include territories that are lagged behind, with the $\mathrm{IOH}$ in the lower limit of distribution. In comparing the north and south areas of El

\footnotetext{
l Licenciado en Economía con Maestría en Dirección de Empresas, cuenta con estudios de macroeconomía aplicada, econometría, programación financiera, entre otros recibidos en diferentes países de Latinoamérica. Recientemente se ha desempeñado como consultor internacional del Centro Latinoamericano para el Desarrollo Rural (RIMISP), investigador del Banco Central de Reserva de El Salvador, profesor de maestría de la Universidad de El Salvador y director del Banco de Desarrollo de El Salvador.
} 
límite inferior de la distribución. Entre el norte y el sur de El Salvador, las oportunidades son mayores en el sur (costero) que en el norte (montañoso). Asimismo, se destaca que los municipios más interconectados, menos pobres multidimensionales, con menor ruralidad y en algunos casos con menor vulnerabilidad socioeconómica ante el cambio climático son los que han mantenido o mejorado su estatus de oportunidad.

\section{Palabras clave}

Calidad de vida; Desarrollo humano; Pobreza; Desigualdad económica regional; Desarrollo rural.
Salvador, the opportunities are higher in the south (coastal area) than in the north (the mountains). In like manner, it is evident that the municipalities that are more interlinked, are less multidimensionally poor, which have less rurality and, in some cases, show a lower socioeconomic vulnerability in the face of climate change, are those which have either improved or maintained their opportunity status.

\section{Keywords}

Life quality; Human Development; Poverty; Regional economic Inequality; Rural development.

\section{Introducción}

Latinoamérica es una región de disparidades que se expresan en oportunidades desiguales entre sus habitantes (Barros et al., 2008); en El Salvador, dicha desigualdad se ha convertido en un componente inherente a la sociedad, un mal estructural que se acepta y cuyas consecuencias son parte del diario vivir de su población.

Las manifestaciones de esta problemática son varias, desde limitantes en el acceso a servicios e infraestructura básica, brechas de pobreza evidentes, falta de empleo digno hasta los altos niveles de criminalidad. Aunque las propuestas de solución han sido diversas y con cierto componente estructural, en su mayoría se perciben ávidas de un mayor enfoque de largo plazo con miras a proporcionar una solución definitiva para la sociedad.

Las disparidades son tales que resaltan a simple vista. Basta con observar la distancia entre los promedios urbanos y rurales, donde reside 62,2 y 37,8 \% de la población, respectivamente, en el año 2013, para tomar conciencia de la magnitud de las brechas internas en las oportunidades.
Un ejemplo de lo anterior es un desempleo urbano consistentemente menor al rural; un 5,6 \% de la población económicamente activa (PEA) desocupada, que se incrementa a 6,6 \% a nivel rural. Asimismo, la pobreza monetaria urbana alcanza un 26,2 \% de los hogares de dicha área, siendo un 5,7 \% de los mismos pobres extremos y el 20,5\% pobres relativos; ${ }^{2}$ mientras que en el área rural el porcentaje sube a un 36,0 \% de hogares, de los cuales el 9,8 \% están en pobreza extrema y el $26,2 \%$ en pobreza relativa.

En la educación, la historia no es distinta. El promedio de años de estudio de la PEA en el área urbana es de 9.2, mientras que en la rural disminuye a 5.6. Además, la tasa de analfabetismo de las personas de 10 años y más alcanza un 7, 61 \% en el área urbana y se dispara a $18,9 \%$ en la rural.

Todas estas desigualdades se trasladan a las oportunidades de desarrollo de los niños, los cuales representan un $30 \%{ }^{3}$ de la población total. A pesar de un progreso notable en materia de cobertura educativa, todavía el $21 \%$ de los niños entre 6 y 14 años no tienen algún año de estudio aprobado; y el 12,7 \% de los de 4 a 15 años no asiste a educación formal. En este último grupo, un $94 \%$ no lo hace porque necesita trabajar; porque lo consideran muy caro; porque no existen escuelas cercanas o

2 Pobreza extrema y pobreza relativa son dos términos que clasifican la medición unidimensional de la pobreza, la cual es estimada por la Dirección General de Estadística y Censos del Ministerio de Economía. En el primer caso, corresponde a aquellos hogares que con su ingreso per cápita no alcanzan a cubrir el costo per cápita de la canasta básica alimentaria (CBA); y en el segundo, se encuentran los hogares que con sus ingreso per cápita no alcanzan a cubrir el costo de la CBA ampliada (dos veces el valor de la CBA).

3 Niños de 0 a 15 años de edad en el año 2013. 
por otros motivos diferentes a enfermedad o discapacidad. De ahí que es lógico que el número de niños y adolescentes, con edades entre 5 a 17 años, que se encuentran en situación de trabajo infantil sea de 144.168.

Es así como las estadísticas nacionales señalan que el acceso a las oportunidades de los menores no es igualitario en el país. A pesar de que son una parte esencial del desarrollo de las sociedades, hasta la fecha no se ha realizado una medición territorial de estas.

En ese sentido, la medición de las oportunidades humanas con perspectiva territorial se convierte en un instrumento que provee de información relevante para la solución estructural de la problemática, ya que permite correcciones tempranas en cuanto al acceso a infraestructura y servicios básicos para los niños, cuyo resultado potencia su desarrollo en su vida adulta y el de la sociedad en general.

Adicionalmente, la importancia de la medición de las oportunidades también se enmarca en la idea de un crecimiento económico inclusivo al estilo de Ali y Zhuang (2007), quienes se refieren a este como un "crecimiento con igualdad de oportunidades", que además "asegura igual acceso a las oportunidades creadas para todos los segmentos de la sociedad".

Esta noción de crecimiento implica un nivel de participación más elevado de la población en la generación del valor agregado, que puede expresarse desde la creación de unidades productivas, para la oferta de bienes y servicios, hasta formas más comunes como el empleo.

Minsky $(2008,2013)$ resalta la importancia que tiene el empleo en un crecimiento económico sostenido y adecuado. Así mismo, Hausmann y Klinger (2007), Hidalgo (2007), Hausmann, Hwan y Rodrik (2005) y Jesús Felipe (2010) entienden que la generación de un empleo de calidad es producto de condiciones factoriales que minimicen los costos asociados con la absorción de nuevas tecnologías, generalmente complejas, que además de permitir la producción de alto valor propician la diversificación de su estructura productiva.

Por lo tanto, la facilitación de las oportunidades en los niños no se puede desvincular del progreso tecnológico y productivo de los territorios, ya que las oportunidades generalmente se expresan en mejores empleos que aportan al crecimiento económico, lo cual, a su vez, propicia condiciones de vida adecuadas por la mayor generación de ingresos.
Como las oportunidades de los menores para acceder a un empleo y a mejores ingresos en el futuro están condicionadas a su entorno, el análisis de cómo es que este se constituye ayuda a crear soluciones efectivas en los espacios con carencias en el entorno. Deesta forma se contribuye a equiparar las oportunidades indistintamente del lugar de residencia de los niños.

El presente trabajo parte de asumir que las oportunidades en El Salvador se encuentran inequitativamente distribuidas, siendo el territorio un factor relevante al momento de definir el acceso ellas.

Para verificarlo, se formularon las siguientes preguntas de investigación: i) ¿Cómo están distribuidas las oportunidades entre los territorios y cómo estas han cambiado en el tiempo? ii) ¿Cuál es el peso del territorio en comparación con las circunstancias personales al momento de explicar la inequitativa distribución de las oportunidades? y iii) ¿Cuáles son los factores que explican la importancia del territorio?

Para responder a las preguntas, se inició por poner en perspectiva el conjunto de brechas territoriales que caracterizan la desigualdad en el país, a partir de estudios previos abordados desde una perspectiva multidimensional de la pobreza y la vulnerabilidad; así mismo, se provee de un apartado que demuestra que el uso de la información de censos del año 2007 puede ser útil para explicar las desigualdades de un contexto más reciente en El Salvador. Todo lo anterior se encuentra contenido en el capítulo I de este documento.

Adicionalmente, se realizaron dos estimaciones del Índice de Oportunidades Humanas $(\mathrm{IOH})$, la primera con un enfoque territorial y destinada a contestar la pregunta "i", la cual se encuentra detallada en el capítulo ॥; dicha estimación tiene como principal interés evidenciar la inequitativa distribución de las oportunidades en los territorios, desnudar aquellos territorios con urgencia de intervención y propiciar la reorientación de las oportunidades, al mismo tiempo de analizar el cambió de esta distribución en el tiempo.

La segundo estimación, provista en el capítulo III, busca contestar las preguntas "ii" y "iii", tratando de encontrar los factores explicativos de las discrepancias del IOH, por medio del uso de la descomposición de Shorrocks-Shapley de 1999; en este apartado se incluyen estimaciones con circunstancias territoriales que ayudan a separar el poder explicativo de las variables (del IOH) y evaluar su evolución en el tiempo. 
Para concluir, se encuentra un espacio de reflexiones finales, donde se adicionó un componente de recomendaciones basado en la revisión de la literatura de las buenas prácticas en materia de políticas públicas con un componente territorial.

\section{El Salvador, un país de desigualdades territoriales múltiples}

La característica territorial de las desigualdades en el país ha sido explorada en algunas investigaciones previas. Amaya y Cabrera (2013) ofrecen un panorama territorial, a escala de municipios de El Salvador, de las desigualdades internas, a través del cálculo de un índice de pobreza multidimensional (IPM) basado en la metodología de la Oxford Poverty \& Human Development Initiative (OPHI), la cual sintetiza en un indicador las características del entorno en que habitan los pobladores de los municipios, tal como el nivel educativo de los jefes de hogar, el grado de asistencia a la escuela de los niños, los niveles de mortalidad infantil, el origen del agua, la modalidad del servicio sanitario, el tipo de alumbrado en el hogar, material del piso, tipo de combustible que utiliza y equipamiento general como automóvil, refrigerador, teléfono u otro.

Por su amplitud, el IPM puede ser utilizado para tener una primera visión de la distribución de las oportunidades de los niños en el territorio, en la misma línea de lo trabajado por Escobal (2012). El gráfico 1 confirma que las desigualdades evidenciadas en los promedios nacionales, corresponden efectivamente a una dispersión de la pobreza multidimensional desigual, siendo más grave en las periferias del territorio salvadoreño (franjas norte y sur), muy coincidente con la ubicación de las zonas menos urbanizadas; por el contrario, la pobreza multidimensional de los centros urbanos (franja central), que cuentan con mayor actividad económica, es de menor magnitud.

Los municipios del departamento de Morazán, como Cacaopera, Corinto, Guatajiagua, Joateca, San Isidro, San Simón, Torola y Yamabal; algunos del norte de San Miguel, como Carolina, Nuevo Edén de San Juan, San Antonio y San Gerardo; el municipio de Guaymango, en Ahuachapán, y otros representan la expresión inequívoca de la desigualdad territorial, ya que registran altas tasas de pobreza multidimensional que contrastan con los resultados de otros municipios, cuyos IPM son claramente inferiores. Entre estos últimos destacan los pertenecientes a San Salvador, como Apopa, Ayutuxtepeque, Cuscatancingo, llopango, Mejicanos, San Marcos, San Martín, San Salvador, Soyapango, Tonacatepeque y Ciudad Delgado; junto con algunos de La Libertad, como Antiguo Cuscatlán, Colón, Nuevo Cuscatlán y Santa Tecla, así como otros municipios de Santa Ana y San Miguel.

Gráfico 1. Mapa de pobreza multidimensional de El Salvador

\section{ג. El Salvador: Mapa de Pobreza Multidimensional}

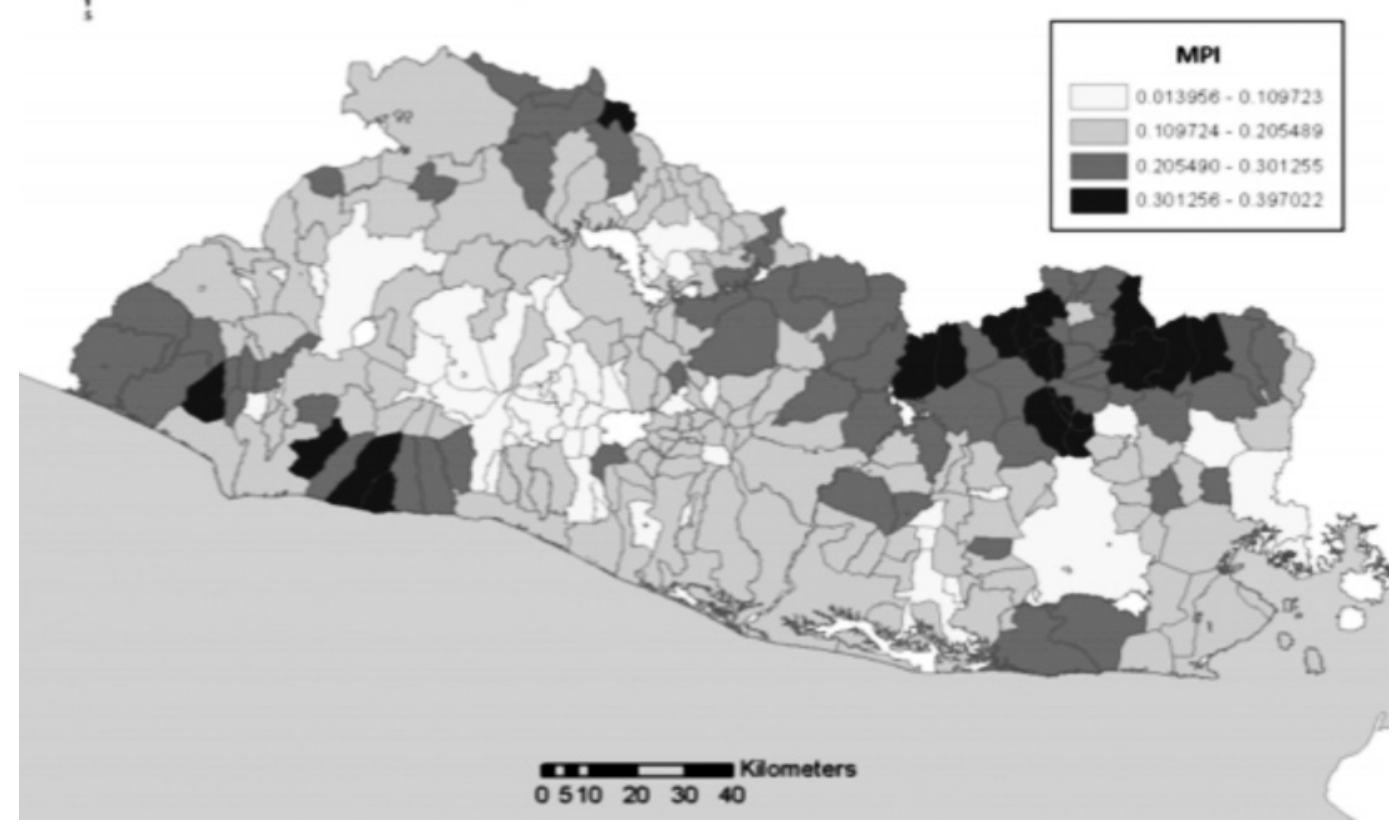

Fuente: Amaya y Cabrera (2013). 
Los patrones territoriales con brechas de pobreza marcadas sugieren que las necesidades de capitalización de estas zonas son disímiles, lo que se expresa en diferentes requerimientos de capital físico y humano y, por lo tanto, en diferentes niveles de inversión. Las zonas del norte y del sur precisan de construcciones básicas que suministren una infraestructura primaria para el desarrollo de las capacidades; mientras que la mayor parte de la zona central requiere del máximo aprovechamiento de las ventajas que los territorios ofrecen para lograr el desarrollo pleno de las capacidades de los niños, lo cual en términos económicos se traduce en incrementos de productividad en su vida adulta.

Otro estudio de Amaya y Cabrera (2013) muestra la distribución de las vulnerabilidades socioeconómicas ante el cambio climático entre los municipios, la cual en muchos de ellos, como en las partes alta y baja de San Miguel, la zona norte de La Unión y algunos municipios de La Libertad están en sintonía con la distribución de la pobreza multidimensional. (Véase el gráfico 2.) En este sentido, la valoración más importante de esta comparación es que la exposición a dichas vulnerabilidades, aunado a un entorno de pobreza, son condicionantes indiscutibles de las menores oportunidades de los niños que habitan dichas regiones y que, por lo tanto, son territorios con urgencias de intervención.

Dado que buena parte de los condicionantes de las oportunidades son territorialmente identificables, se vuelve atinado utilizar la métrica del $\mathrm{OH}^{4}$ para evidenciarlas; sin embargo, el cálculo territorial del $\mathrm{IOH}$ requiere de estadísticas robustas a un máximo nivel de desagregación territorial, que para el caso salvadoreño están contenidas en los VI Censo de Población y V de Vivienda realizados en el año 2007.

Dichos censos representan 8 años de desfase con respecto al año 2015, por lo que fue necesario encontrar un mecanismo de verificación que permitiera testear si la distribución de las condiciones y oportunidades derivadas de su uso sigue teniendo vigencia, ante la ausencia de un nuevo censo de población y vivienda que las actualice.

Gráfico 2. Mapa de distribución del Îndice de Vulnerabilidad Socioeconómica ante el cambio climático de El Salvador

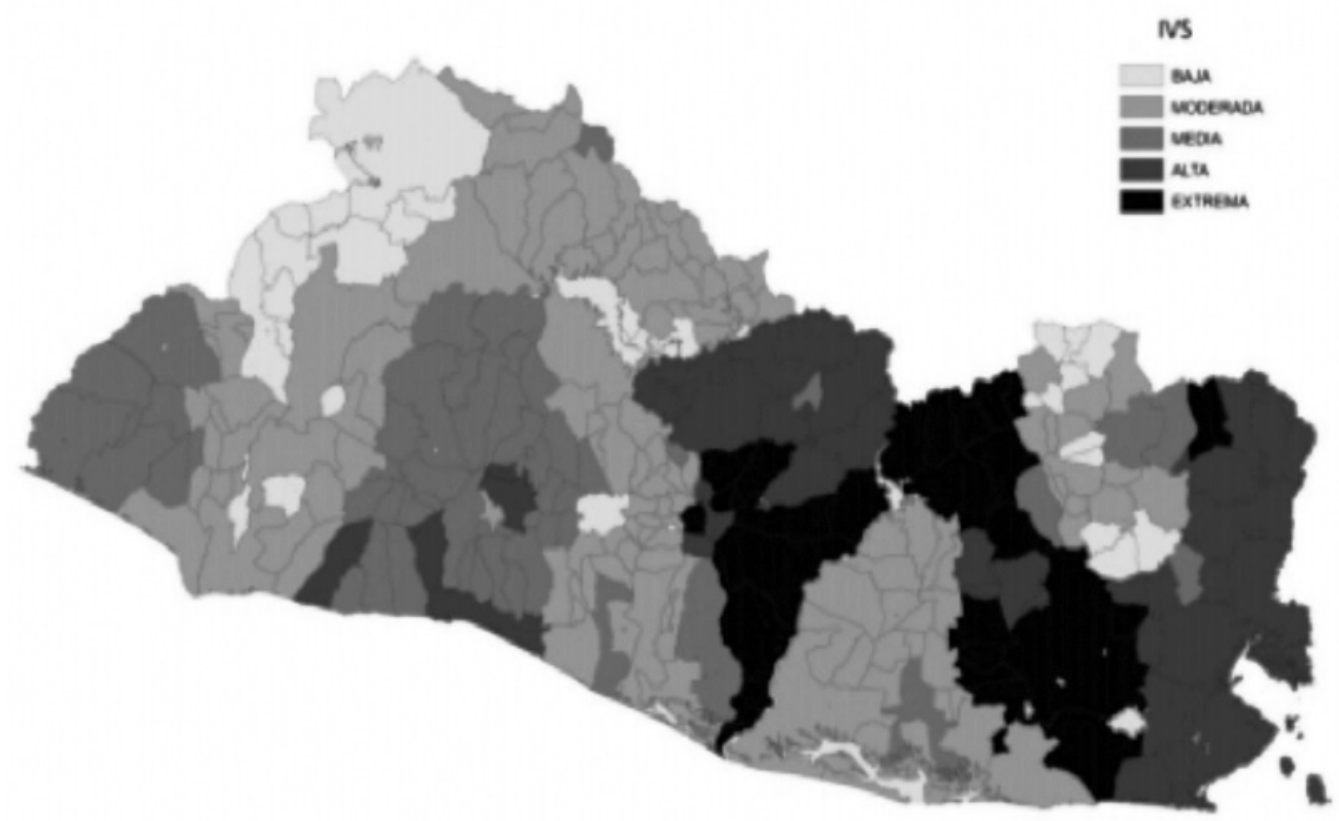

Fuente: Amaya y Cabrera (2013).

\footnotetext{
4 La metodología del IOH se explica en detalle en el capítulo II.
} 


\section{a. El problema de las estadísticas básicas en El Salvador}

El instrumento territorial que más se aproxima a este detalle (municipal) son las encuestas de hogares de propósitos múltiples (EHPM), cuya representatividad máxima es a escala de los departamentos de El Salvador, primer nivel de división administrativa del país y que agrupa a un conjunto de municipios. La estrategia de verificación consistió en hacer un uso comparativo de los resultados de la encuesta del año 2007 versus los de la del año más reciente disponible, 2013, para comprobar si la hipótesis de una distribución espacial relativamente invariante de las condiciones territoriales tiene validez, permitiendo así un análisis "actual" de las brechas en el estilo de vida de los pobladores a partir de los datos de censos.

Las variables derivadas del uso de las EHPM tienen un menor detalle que las que se obtienen del uso de censos, por lo tanto, solamente algunas de ellas fueron evaluadas en este ejercicio. Los resultados de este análisis comparativo son únicamente indicativos que sirven para referenciar dos contextos en el tiempo, que a su vez sugieren que un conjunto de circunstancias más amplio podría o no conservar su distribución en el período analizado.

La comparación, detallada en el anexo 1, demostró que en la mayoría de los casos existe una relativa permanencia de las desigualdades territoriales en el año 2013 respecto a las registradas en el 2007. Aun cuando hay cambios internos en los dos segmentos de la distribución, estos siguen siendo relativamente bajos, insuficientes para cambiar la mayoría de las posiciones de los territorios respecto al promedio nacional; por lo tanto, las conclusiones obtenidas del análisis de los censos de población y vivienda del año 2007 tienen una alta probabilidad de estar vigentes, sobre todo en cuanto a las brechas territoriales se refiere.

Sin embargo, se reconoce la necesidad de contar con estadísticas básicas actualizadas en el país, en primer lugar por los cambios internos mencionados anteriormente, y en segundo, por el menor grado de dispersión en algunos indicadores, algo importante que se debe reconocer en torno a la reducción actual de la distancia en las disparidades que no se reflejan en los cálculos del IOH basados en información del año 2007, lo que constituye una limitante de este trabajo.

\section{Las oportunidades humanas en el territorio}

\section{a. La métrica de las oportunidades. El Índice de Oportunidades Humanas (IOH)}

Se estimó el índice de Oportunidades Humanas bajo la metodología propuesta, Roemer (1998), y aplicada por el Banco Mundial, Roemer y Trannoy (2013), Barros et al. (2010), Escobal (2012) y Hoyos y Narayan (2012). De forma resumida, la metodología reconoce que "mientras haya niños en un país sin acceso a servicios básicos para el desarrollo futuro de sus vidas (como por ejemplo, la educación primaria o el agua potable), y en la medida que el acceso está influenciado por circunstancias, la desigualdad de oportunidades prevalecerá" (Barros et al., 2008).

Las circunstancias pueden ser tanto personales como territoriales, ambas están fuera de control por parte de los individuos estudiados; las circunstancias tratan de explicar la probabilidad que tiene un niño para acceder a una ventaja determinada. Algunos ejemplos encontrados en la literatura son el sexo del jefe de hogar, la etnicidad, el lugar de nacimiento, la institucionalidad del territorio, etc.

Matemáticamente el $\mathrm{IOH}$ está definido por una cobertura promedio de una ventaja (c), la cual es ponderada por la desigualdad en su distribución (1-D). La desigualdad se calcula estimando la probabilidad de acceso a la ventaja de los individuos " $k$ ", la cual es una función de las circunstancias que determinan el hábitat del individuo.Ladesigualdad se calcula con la fórmula:

$$
\mathrm{D}=\frac{1}{2 \mathrm{c}} \sum_{\mathrm{k}=1}^{\mathrm{m}}\left|\mathrm{c}_{\mathrm{k}}\left(\mathrm{x}_{\mathrm{k}}\right)-\mathrm{c}\right| \beta_{\mathrm{k}} \mid
$$

En la fórmula, $\mathrm{c}_{\mathrm{k}}\left(\mathrm{x}_{\mathrm{k}}\right)$ es la función de probabilidad del individuo para acceder a la ventaja, estimada mediante un modelo probit o logit; " $\beta_{\mathrm{k}}$ " indica la participación en la población de cada uno de estos $k$ individuos, $y$ " $c$ " corresponde al nivel promedio de cobertura de la ventaja.

Al obtener el nivel de desigualdad en la distribución, se puede estimar su complemento de manera que se construye el $\mathrm{IOH}$ :

$$
\operatorname{IOH}(\text { ventaja } \mathrm{j})=\mathrm{c}_{\mathrm{j}}(1-\mathrm{D}(\mathrm{j}))
$$


El valor del $\mathrm{IOH}$ incrementa cuando la cobertura promedio de la ventaja $c_{j}$ incrementa; por el contrario, baja cuando la distribución es más desigual (1-D(j)), de esta forma el IOH no solo captura el esfuerzo por lograr cobertura, sino también la brecha en la distribución entre los individuos analizados.

La aplicación para el caso de El Salvador consistió en una estimación territorial del $1 \mathrm{OH}$ para los dos últimos años en que se realizaron los censos de población y vivienda (1992 y 2007). La desagregación territorial elegida fueron los territorios funcionales estimados por Amaya y Cabrera (2012).

Un territorio funcional se define como "el espacio que contiene una alta frecuencia de interacciones económicas y sociales entre sus habitantes, sus organizaciones y sus empresas". (Berdegué, et al., 2011. pág. 8), por lo tanto, utilizarlos en este trabajo como definición de territorio se consideró adecuado debido a que permite incorporar la identificación oportuna de los límites territoriales internos basados en las relaciones "reales" que se suscitan entre la población de dichos territorios; y que en ocasiones difiere de la división administrativa del país.

Los territorios funcionales de Amaya y Cabrera (2012) dividen al país en 218 territorios, diferente a los 262 municipios administrativos. El anexo 2 contiene el listado de territorios funcionales identificados en El Salvador.

El universo de análisis para el cálculo del IOH son los niños menores de 15 años de edad, las bases de datos utilizadas provienen de los IV Censos de Población y III de Vivienda de El Salvador del año 1992 y de los V Censos de Población y IV de Vivienda de El Salvador del año 2007. Dicha información proviene de la Dirección General de Estadística y Censos de El Salvador (Digestyc). ${ }^{5}$

Para responder las preguntas de investigación, se realizaron dos estimaciones del $\mathrm{IOH}$ con especificaciones diferentes que varían en la incorporación de algunas circunstancias territoriales, lo cual fue útil para armonizar la disponibilidad de información entre censos.

\section{b. Distribución del IOH en el territorio nacional}

Este primer apartado tiene por objetivo contestar la pregunta uno de la investigación, consistente en verificar si la distribución de las oportunidades entre los territorios es homogénea en la actualidad y cómo estas han cambiado en el tiempo.
Para poder realizarlo, se debió construir una base de datos referenciada al hogar de cada uno de los niños analizados con el fin de caracterizar el entorno en función de un conjunto de circunstancias personales igualmente definidas para ambos años, lo que garantiza la comparación en el tiempo. Las circunstancias utilizadas en la especificación territorial de este apartado se encuentran resumidas en el cuadro 1.

Dichas circunstancias determinan el nivel de acceso a un conjunto de ventajas, que se consideran importantes para determinar el nivel de desarrollo de los niños, ya que se refieren a una gama de servicios e infraestructura básica que permite la realización de los derechos como ser humano.

El cuadro 2 resume las ventajas incorporadas en el cálculo; la elección de estas ventajas y sus respectivas justificaciones fueron retomadas en su mayoría de Tomaselli (2014). El agua potable y el saneamiento adecuado son reconocidos por las Naciones Unidas como una necesidad para la realización de los derechos humanos en términos de salud; el acceso a la energía eléctrica es importante para el correcto desempeño de las labores educativas asociadas con incrementos de productividad; tener una vivienda apropiada y el menor hacinamiento en el hogar garantizan una protección del medio natural y las mejoras de salud, tal como lo reconocen la Comisión Económica para América Latina y el Caribe y el Programa de las Naciones Unidas para el Desarrollo .

Así mismo, se destaca la educación con una indiscutible asociación con los incrementos de productividad de las personas; el acceso a un refrigerador como instrumento para el almacenamiento adecuado de los alimentos, identificado por la Organización de las Naciones Unidas para la Alimentación y la Agricultura y la Organización Mundial de la Salud; y la tecnología de la información representada por el acceso a telefonía, como instrumento que facilita el aprendizaje, el comercio y otros aspectos relacionados con la generación de ingresos en los hogares.

En la estimación del modelo logit se prefirió la estabilidad numérica en el proceso de optimización, al permitir que Stata eliminara los coeficientes y las observaciones de los predictores perfectos. Esta acción no tiene algún efecto sobre la verosimilitud o en la estimación de los coeficientes restantes.

\footnotetext{
5 Algunos ajustes fueron necesarios para depurar la base de datos de los años 1992 y 2007, tal como haber ignorado a los niños presentes en los hogares colectivos y a los niños sin hogar, debido a que no se identificó al jefe del hogar del mismo ni la composición del hogar, esto debido a que todos los miembros fueron catalogados con códigos idénticos. Los niños ignorados en censos de 1992 sumaron 2.377 del total de niños censados de 2.113 .343 , es decir el 0,11 \% del total; mientras que, en censos de 2007, los niños ignorados sumaron 2.819 del total de la muestra de 2.075 .242 es decir un 0,14 \% omitidos.
} 
Cuadro 1. Conjunto de Circunstancias identificadas en Censos 1992 y 2007

\begin{tabular}{|c|c|c|}
\hline VARIABLE & DESCRIPCIÓN & VARIABLE DICOTÓMICA \\
\hline SEXOM & sexo del menor & $1=$ hombre, $0=$ mujer \\
\hline SEXOJH & $\begin{array}{l}\text { Sexo del jefe de } \\
\text { hogar en el que } \\
\text { vive el niño }\end{array}$ & $1=$ hombre, $0=$ mujer \\
\hline EDUCJH1 & $\begin{array}{l}\text { Educación del } \\
\text { jefe de hogar }\end{array}$ & $\begin{array}{c}1 \text { = cuenta con primaria, } 0 \\
=\text { Otro nivel, no cuenta } \\
\text { con educación formal o no } \\
\text { responde }\end{array}$ \\
\hline EDUCJH2 & $\begin{array}{l}\text { Educación del } \\
\text { jefe de hogar }\end{array}$ & $\begin{array}{c}1=\text { cuenta con } \\
\text { secundaria, } 0=\text { Otro nivel, } \\
\text { no cuenta con educación } \\
\text { formal o no responde }\end{array}$ \\
\hline EDUCJH3 & $\begin{array}{l}\text { Educación del } \\
\text { jefe de hogar }\end{array}$ & $\begin{array}{l}1 \text { = cuenta con educación } \\
\text { superior, } 0=\text { Otro nivel, } \\
\text { no cuenta con educación } \\
\text { formal o no responde }\end{array}$ \\
\hline HMONOP & $\begin{array}{c}\text { Hogar } \\
\text { monoparental }\end{array}$ & $\begin{array}{c}1=\text { monoparental, } 0=\text { no es } \\
\text { monoparental }\end{array}$ \\
\hline ML_TMH & $\begin{array}{l}\text { Miembros del } \\
\text { hogar en el } \\
\text { mercado } \\
\text { laboral/total } \\
\text { miembros del } \\
\text { hogar }\end{array}$ & $\begin{array}{c}\text { Personas que } \\
\text { trabajan/total de } \\
\text { personas }\end{array}$ \\
\hline OCUPJH1 & $\begin{array}{l}\text { Ocupación del } \\
\text { jefe de hogar }\end{array}$ & $\begin{array}{c}1=\text { sector primario } \\
\text { (códigos de } 0-14 \text { ), } \\
0=\text { Otro caso o no declara }\end{array}$ \\
\hline OCUPJH2 & $\begin{array}{l}\text { Ocupación del } \\
\text { jefe de hogar }\end{array}$ & $\begin{array}{c}1=\text { sector } \\
\text { secundario(códigos de } 15- \\
37 \text { y } 45 \text { ), } 0 \text { = Otro caso o } \\
\text { no declara }\end{array}$ \\
\hline OCUPJH3 & $\begin{array}{l}\text { Ocupación del } \\
\text { jefe de hogar }\end{array}$ & $\begin{array}{c}1=\text { sector terciario(códigos } \\
\text { de } 40-41 \text { y } 50 \text { en } \\
\text { adelante), } 0=\text { Otro caso o } \\
\text { no declara. }\end{array}$ \\
\hline
\end{tabular}

Elaboración propia con base en Tomaselli 2014.
Cuadro 2. Conjunto de Ventajas identificadas en Censos 1992 y 2007

\begin{tabular}{|c|c|c|}
\hline VARIABLE & DESCRIPCIÓN & VARIABLE DICOTÓMICA \\
\hline AGUAP & $\begin{array}{l}\text { Acceso de la } \\
\text { vivienda a agua } \\
\text { potable (red } \\
\text { pública o agua } \\
\text { tratada) } \\
\end{array}$ & $\begin{array}{l}1=\text { tiene acceso a agua } \\
\text { potable, } 0=\text { no tiene } \\
\text { acceso a agua potable }\end{array}$ \\
\hline SANEAM & $\begin{array}{c}\text { Acceso de la } \\
\text { vivienda a } \\
\text { saneamiento } \\
\text { (servicios } \\
\text { higiénicos } \\
\text { conectados a red } \\
\text { pública o fosa } \\
\text { séptica) }\end{array}$ & $\begin{array}{c}1=\text { tiene acceso a } \\
\text { saneamiento, } 0=\text { no } \\
\text { tiene acceso a } \\
\text { saneamiento }\end{array}$ \\
\hline ENERGIA & $\begin{array}{c}\text { Disponibilidad de } \\
\text { energía eléctrica } \\
\text { en la vivienda (por } \\
\text { cualquier medio: } \\
\text { red pública, } \\
\text { generador propio } \\
\text { o comunitario) }\end{array}$ & $\begin{array}{c}1=\text { tiene acceso a } \\
\text { energía eléctrica, } 0=\text { no } \\
\text { tiene acceso a energía } \\
\text { eléctrica }\end{array}$ \\
\hline VIVIENDA & \begin{tabular}{|c|} 
Materialidad de la \\
vivienda (según \\
las clasificaciones \\
calidades de los \\
pisos, muros y \\
techos) \\
\end{tabular} & $\begin{array}{c}1=\text { tiene acceso a } \\
\text { vivienda adecuada, } 0= \\
\text { no tiene acceso a } \\
\text { vivienda adecuada }\end{array}$ \\
\hline $\mathrm{NOHACl}$ & $\begin{array}{c}\text { Hogar no hacinado } \\
\text { (según definición } \\
\text { de pnud, } \\
\text { considerando a los } \\
\text { hogares donde } \\
\text { conviven menos } \\
\text { de } 2.5 \text { personas } \\
\text { por dormitorio) }\end{array}$ & $\begin{array}{c}1=\text { el hogar no es } \\
\text { hacinado }(p / d<2.5), 0= \\
\text { hogar hacinado }(p / d>= \\
2.5)\end{array}$ \\
\hline ASISTENCIA & $\begin{array}{c}\text { Asistencia a la } \\
\text { escuela }\end{array}$ & $\begin{array}{c}1=\text { el niño asiste } \\
\text { actualmente a la } \\
\text { escuela, } 0=\text { no asiste } \\
\text { actualmente a la } \\
\text { escuela }\end{array}$ \\
\hline ESCOLAT & $\begin{array}{l}\text { Escolaridad a } \\
\text { tiempo }\end{array}$ & $\begin{array}{c}1=\text { el niño asiste } \\
\text { actualmente a la } \\
\text { escuela a tiempo, } 0=\text { no } \\
\text { asiste actualmente a la } \\
\text { escuela a tiempo }\end{array}$ \\
\hline REFRI & $\begin{array}{c}\text { Hogar con acceso a } \\
\text { refrigerador }\end{array}$ & $\begin{array}{c}1=\text { la vivienda tiene } \\
\text { refrigerador, } 0=1 \mathrm{a} \\
\text { vivienda no tiene } \\
\text { refrigerador }\end{array}$ \\
\hline TELEFONO & $\begin{array}{c}\text { Hogar con acceso a } \\
\text { telefonía fija o } \\
\text { móvil }\end{array}$ & $\begin{array}{c}1=\text { la vivienda tiene } \\
\text { teléfono } 0=\text { la vivienda } \\
\text { no tiene teléfono }\end{array}$ \\
\hline
\end{tabular}

Elaboración propia con base en Tomaselli 2014. 


\section{Los resultados territoriales}

La evaluación comparativa desveló cambios territoriales importantes, reflejados en los valores extremos tomados por el $\mathrm{IOH}$. El valor mínimo promedio (promedio de todas las ventajas) pasó de 13.6 en 1992 a 30.9 unidades en 2007, así como el máximo valor de la distribución que subió de 63.6 a 82.14, manteniendo en ambos años aproximadamente 12.5 puntos de rango. Este movimiento al alza lleva implícito un aumento generalizado en la probabilidad que tienen los niños de acceder a las oportunidades en el país, derivado tanto por los esfuerzos de cobertura como por la disminución de las distancias entre los pobladores. (Véase el gráfico 3.)

Se confirman también algunos patrones territoriales mencionados en el capítulo I, que además son constantes en el tiempo en menor o mayor intensidad en algunas regiones. La franja central de El Salvador, identificada por el corredor de las principales ciudades, Santa Ana, San Salvador, la parte norte de la Libertad y San Miguel, evidencian tener mejores oportunidades de desarrollo que el resto del país. Las franjas norte y sur poseen territorios rezagados con niveles de $\mathrm{IOH}$ en el límite inferior de la distribución; entre el norte y el sur, las oportunidades son mayores en el sur (costero) que en el norte (montañoso).

Así mismo, se destaca que los terrenos más interconectados, menos pobres multidimensionales, con menor ruralidad y en algunos casos con menor vulnerabilidad socioeconómica ante el cambio climático, como los cercanos a la capital, San Salvador, son los que han mantenido o mejorado su estatus de oportunidad. Mientras que los territorios menos urbanos, con menor conectividad y mayor pobreza multidimensional, como los territorios del norte de San Miguel, algunos de Morazán, Ahuachapán y Sonsonate presentan evidentes carencias que definen la baja oportunidad de sus niños y jóvenes.

Aunque las oportunidades máximas siguen estando concentradas en los territorios funcionales de San Salvador, Soyapango, Apopa, San Marcos, Ciudad Delgado, Santa Tecla, Cuscatancingo y Mejicanos, otros territorios han progresado extraordinariamente en términos del $\mathrm{IOH}$, tal es el caso de Concepción de Oriente, del departamento de La Unión; San Antonio los Ranchos, de Chalatenango, y Nueva Granada, de Usulután, que pasan de la categoría más baja en 1992 a la categoría tres, ubicada en la parte superior de la distribución en el año 2007.
Así como otros territorios que saltaron un nivel en su categoría de oportunidad, que en total suman 32, repartidos a lo largo del país, donde destacan los pertenecientes al departamento de Morazán, San Miguel y Usulután, que agrupan la mayor cantidad de territorios que progresaron en dicho nivel.

Al subdividir el país en regiones, se vuelven notorios los esfuerzos de inversión realizados en los extremos sur y norte de la parte oriental de El Salvador, en especial en el departamento de Morazán; esto último es importante porque son menos los territorios que registran un $\mathrm{IOH}$ en la categoría inferior, respecto a los que existían en 1992, resultado que apuntala la disminución de las brechas territoriales.

Por otro lado, existen territorios estáticos, marcados por la falta de oportunidades crónica. Estos territorios se ubican históricamente en la cota inferior de la distribución; algunos ejemplos son los pertenecientes al departamento de Morazán, como Torola, San Fernando, Yamabal, Cacaopera, Gualococti; al de Sonsonate, como Cuisnahuat y Santa Isabel Ishuatán; Concepción de Ataco, en Ahuachapán, y Panchimalco en San Salvador. Dichos territorios necesitan de una capitalización focalizada que les ayude a progresar y salir del estancamiento en que se encuentran.

En cuanto al análisis por ventaja, específicamente al acceso a una fuente mejorada de agua mostrada en el gráfico 4, el $10 \mathrm{H}$ indica una mejora significativa que ha contribuido a aumentar las oportunidades en los territorios, principalmente en la franja central del país y en los municipios del departamento de Chalatenango. El esfuerzo se refleja en una subida del $\mathrm{IOH}$ mínimo, que pasa de cero a cuatro unidades, y en el incremento de los territorios con oportunidades superiores en toda la franja central y parte de la franja norte del territorio.

El incremento del $\mathrm{IOH}$ está muy asociado con la mayor cobertura, cuyo valor mínimo pasa de cero a cinco unidades, así mismo el progreso en la disminución de la distancia, que se refleja en una reducción de la amplitud total de la distribución, que pasa de aproximadamente 85 en 1992 a 30 en el año 2007 (ver anexo 3).

Sin embargo, a pesar de los esfuerzos, se observa la permanencia de áreas desprotegidas identificadas en los cuatro extremos del mapa, las regiones rezagadas siguen siendo algunos territorios de la zona norte de La Unión, Morazán, Ahuachapán, Chalatenango y Usulután, los cuales se pueden catalogar como territorios sin progreso relativo, ya 
Gráfico 3. $1 \mathrm{OH}$ promedio 1992 y 2007 por Territorio Funcional de El Salvador
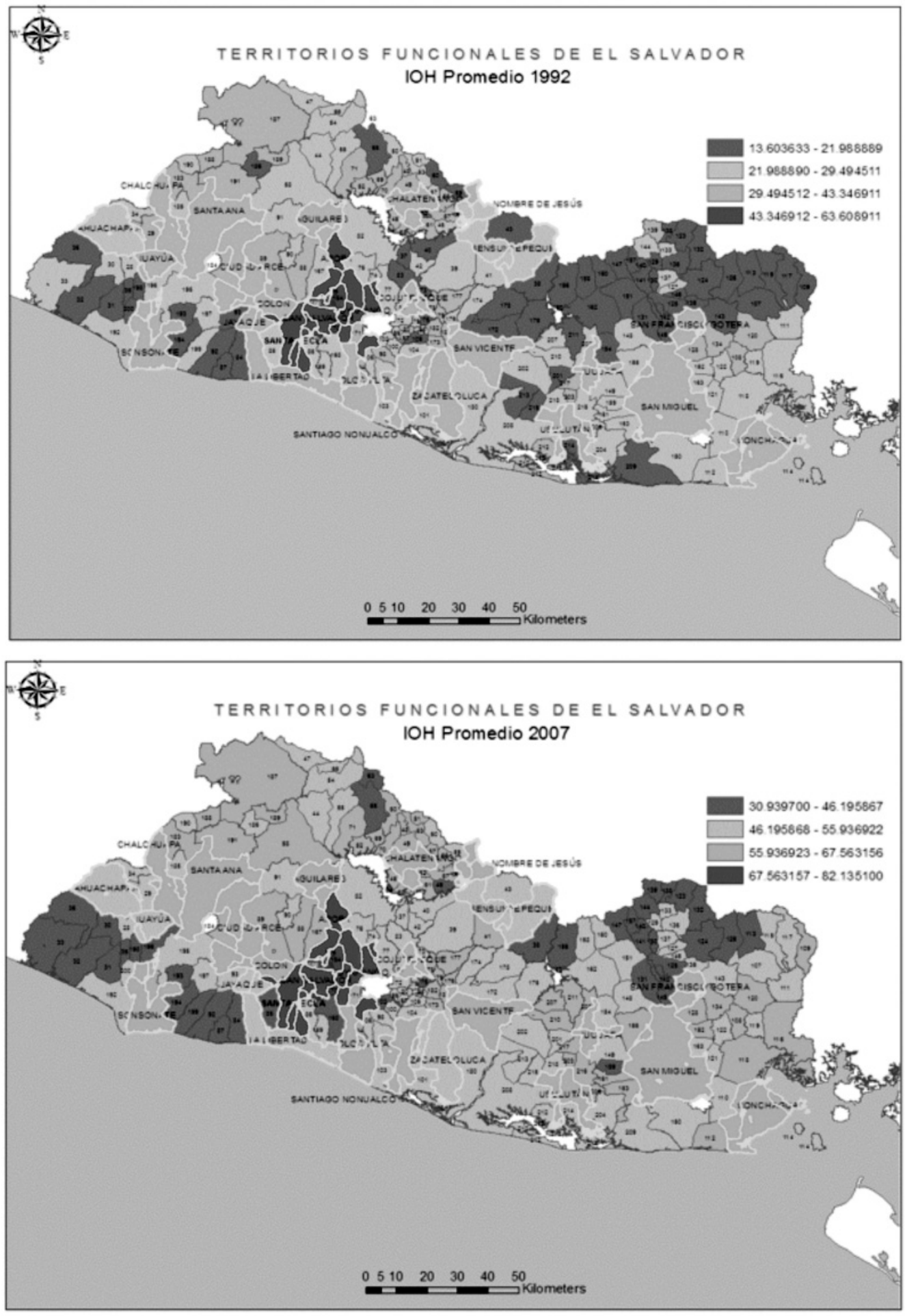

Fuente: Elaboración propia con base en IV Censos de Población y III de Vivienda de El Salvador del año 1992 y de los V Censos de Población y IV de Vivienda de El Salvador del año 2007. 
que conservan su estatus en la categoría inferior que tenían en 1992.

Otro factor importante para generar un ambiente de desarrollo saludable es el acceso a saneamiento. El gráfico 5 muestra un progreso modesto en la distribución de las oportunidades. A primera vista, los mapas parecen similares, sin embargo los datos revelan que 173 de los 218 territorios mostraron algún progreso en el valor de su $1 \mathrm{OH}$, pero en la mayoría de los casos no tan alto como para propiciar cambios generalizados en su categoría.

La excepción la constituyen los territorios con progresos emblemáticos, tal como Cuscatancingo, Las Flores, San Francisco Gotera, Jucuapa, San Isidro, San Francisco Lempa, California, San Agustín, San Francisco Javier y Nueva Granada, cuyos valores del $1 \mathrm{OH}$ trascendieron más de 20 puntos; incremento que está muy relacionado con los aumentos en la cobertura (ver anexo 4).

Estos casos contrastan con otros que sufrieron retrasos, producto de los efectos negativos del incremento en la amplitud de la cobertura por saneamiento, generando que las oportunidades se vuelvan más extensas y las distancias más amplias. Esto ocasionó que algunos territorios bajaran de valor en su IOH, como es el caso de Puerto El Triunfo, Oratorio de Concepción, San Antonio Pajonal, Santa Cruz Analquito, Jocoaitique y Estanzuelas, cuyos deterioros son los más altos de todo el país.

Los aspectos educativos, como la asistencia a la escuela y la escolaridad a tiempo, son otros factores fundamentales del crecimiento y desarrollo de los niños. Dichas ventajas son popularmente reconocidas en cuanto a que tienen un efecto directo que potencia la capacidad de los alumnos para desarrollarse plenamente.

La distribución de la asistencia a la escuela, mostrada en el gráfico 6, evidencia uno de los progresos más importantes de la gestión pública: el aumento del valor del IOH mínimo, que pasa de 41 unidades a cerca de 69; y a la vez, la disminución de la brecha entre los territorios reflejada en un rango menor de la distribución (49.6 en 1992 contra 25.2 en 2007) denota una intención clara por ampliar el acceso a la educación dirigida desde el Estado. También se destaca que son 217 de los 218 territorios los que muestran progresos en el $\mathrm{IOH}$ de esta categoría, sobresaliendo los territorios como Guaymango, San Isidro Labrador, San Antonio, San Isidro y Cinquera, que se mueven de una categoría en el límite inferior de la distribución en 1992 a la máxima en 2007.

El contraste se encuentra en Morazán, específicamente en Cacaopera, Sensembra y Corinto; en La Unión, donde se mencionan Lislique y Anamorós; en San Miguel, con Nuevo Edén de San Juan, Ciudad Barrios, San Gerardo y San Luis de la Reina; junto con Victoria, del departamento de Cabañas. Estos territorios, a pesar de haber mostrado progreso, se mantienen en las categorías inferiores de la distribución, indicando rezagos en el acceso a esta ventaja.

La magnitud de los cambios positivos se explica en buena medida por los esfuerzos públicos de cobertura, tal como se mencionó anteriormente, que pasa de un mínimo de 47 unidades a otro de 72, y cuyos resultados se manifiesta en mayor medida en los territorios cercanos a la zona central, incluyendo la zona central del norte del país. Así mismo, se subraya que el rango en la distribución de la distancia pasó de 11.6 puntos en 1992 a cerca de 8 en el año de 2007 (véase anexo 5). El recuadro 1 contiene un resumen cronológico de los programas ejecutados en el país por parte del Ministerio de Educación.

En lo que respecta a la escolaridad a tiempo, se observa una mejora muy relacionada con la asistencia escolar; Ios saltos del IOH mínimo y máximo son cercanos a 14 puntos. Aunque no se encuentra un movimiento marcado de saltos de categoría entre límites, si se destacan los progresos más importantes en los territorios de Joateca y El Rosario en Morazán, y Nueva Trinidad en Chalatenango. (Véase gráfico 7.)

De nuevo, se observa la permanencia del retraso en los territorios uni-municipales que presentan desfase en asistencia a la escuela; a excepción de Anamorós y Ciudad Barrios. Los movimientos en esta ventaja pueden ser mejor explicados por el incremento de la cobertura más que por la disminución de la distancia (véase anexo 6).

Otra infraestructura básica es el acceso a refrigerador, al teléfono y a la electricidad; estas ventajas tienen en común su alta dependencia de las decisiones privadas, tanto del lado de los ofertantes, por ser un negocio privado, como del de la demanda de los hogares; para el caso específico, de El Salvador.

En estos tres aspectos también se evidenció un progreso notable en términos de oportunidades. El IOH de acceso a refrigerador pasa de valores mínimos de cero a cinco, y en 
Gráfico 4. $\mathrm{IOH}$ en Acceso al Agua 1992 y 2007 por Territorio Funcional de El Salvador
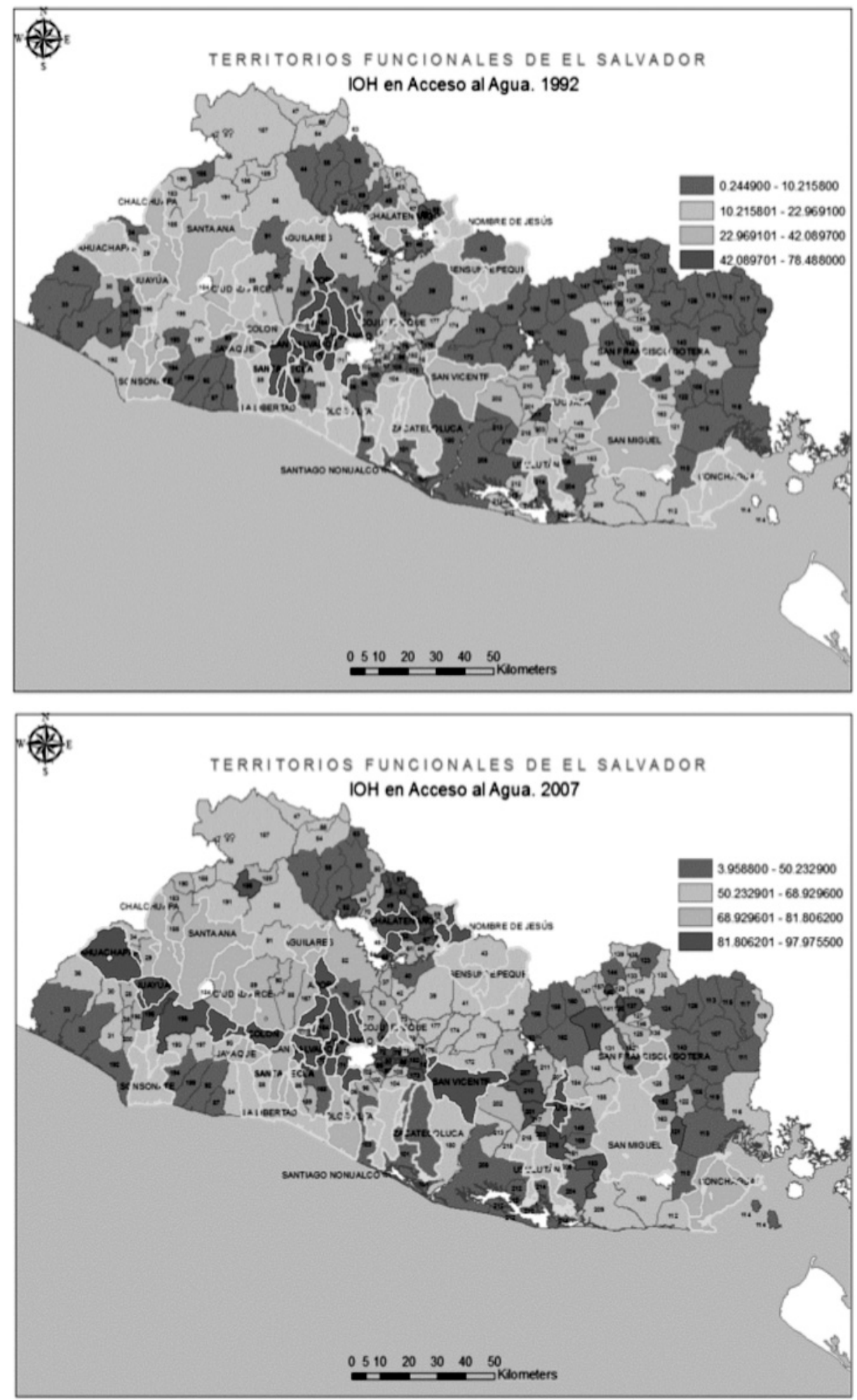

Fuente: Elaboración propia con base en IV Censos de Población y III de Vivienda de El Salvador del año 1992 y de los V Censos de Población y IV de Vivienda de El Salvador del año 2007. 
Gráfico 5. $1 \mathrm{OH}$ en Acceso a Saneamiento 1992 y 2007 por Territorio Funcional de El Salvador
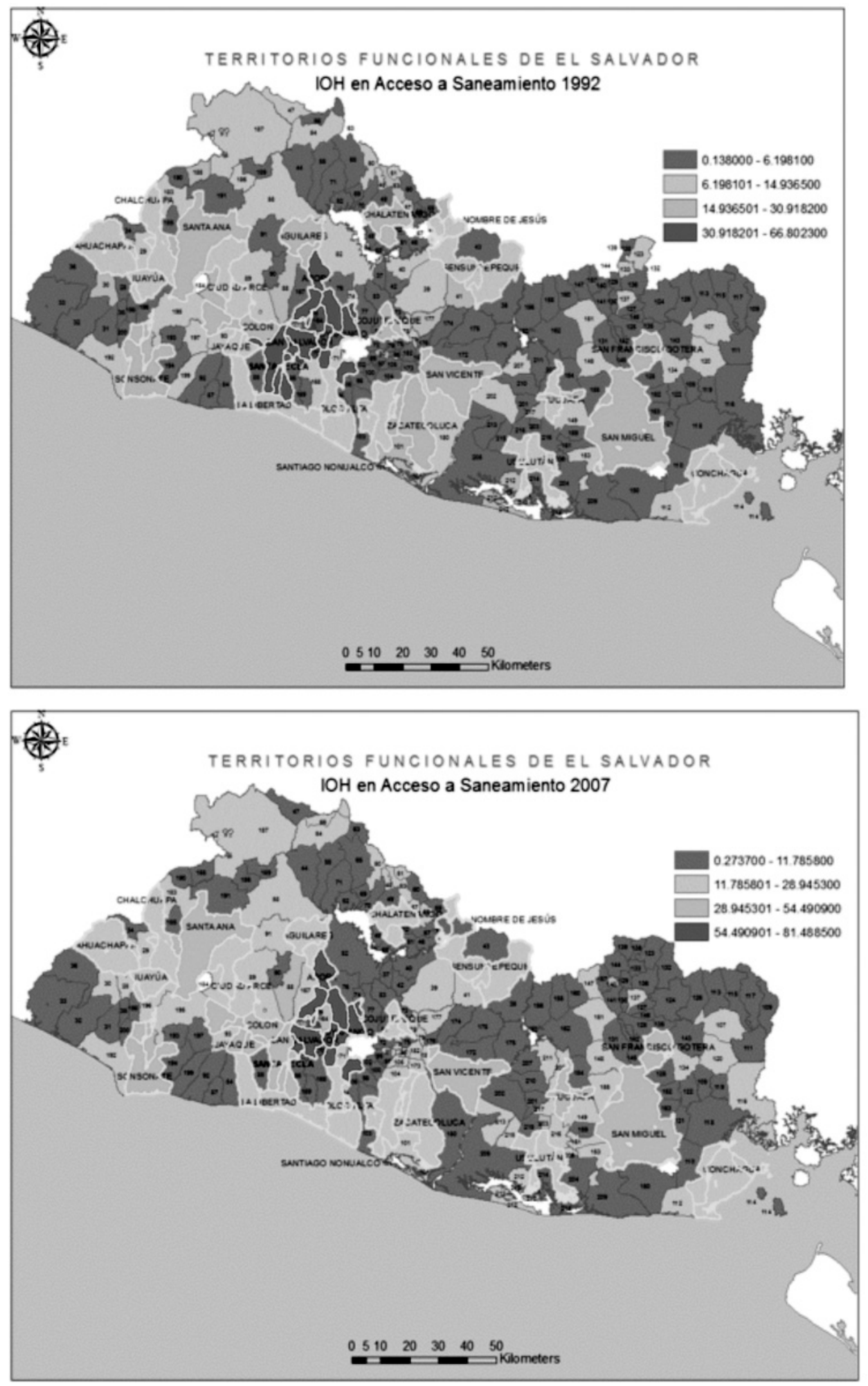

Fuente: Elaboración propia con base en IV Censos de Población y III de Vivienda de El Salvador del año 1992 y de los V Censos de Población y IV de Vivienda de El Salvador del año 2007. 
Gráfico 6. $1 \mathrm{OH}$ en Acceso a Asistencia a la Escuela 1992 y 2007 por Territorio Funcional de El Salvador
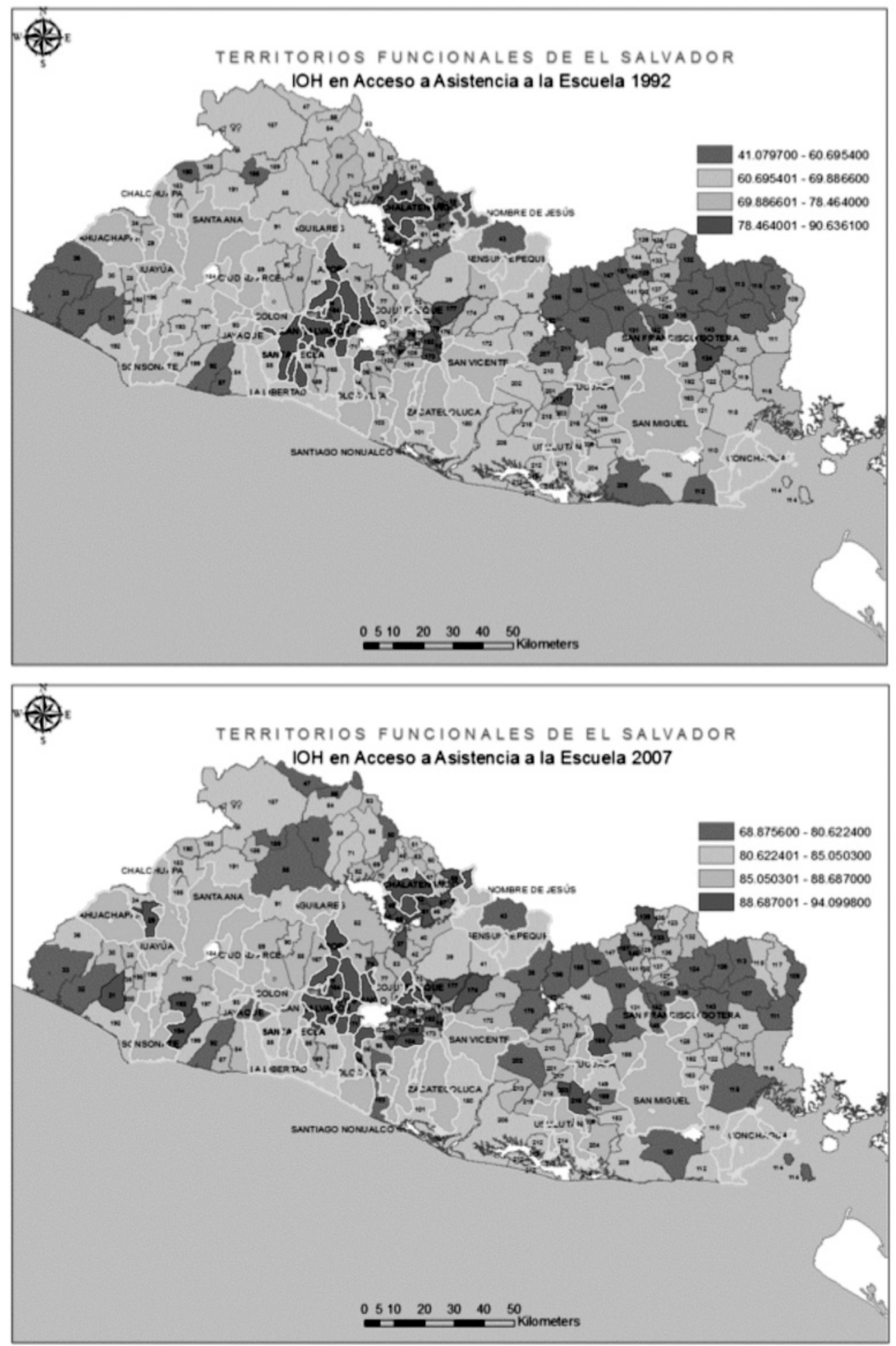

Fuente: Elaboración propia con base en IV Censos de Población y III de Vivienda de El Salvador del año 1992 y de los V Censos de Población y IV de Vivienda de El Salvador del año 2007. 
Recuadro 1. La historia de las políticas de educación en El Salvador

La reforma al sistema educativo en el país ha sido construida sobre la base de una serie de programas que en cierta medida permitieron una coherencia en el tiempo; el resultado más emblemático de esto es el aumento de cobertura de la asistencia escolar.

En 1990 inició el Programa "Educación con Participación de la Comunidad" (Educo), donde se buscó la mejora en la formación docente como eje central mediante capacitaciones y la mejora en la calidad del currículo, entre otros aspectos relacionados.

Entre 1994 y 1999 se impulsó el último proyecto de reforma educativa del país, para el cual se elabora el Plan Decenal de la Reforma Educativa 1995-2005, cuyo contenido se organizó en cuatro ejes fundamentales: Cobertura, Calidad, Formación en valores y Modernización Institucional.

Entre 1995 y 1996 se aprueba una serie de leyes importantes para el fortalecimiento de la reforma: la Ley de Educación Superior, la Ley de la Carrera Docente y la Ley General de Educación, que le dieron un marco institucional clave para el fortalecimiento de la labor docente.

Al finalizar el ciclo del Plan Decenal, a mediados de los años 2000, se lanzó el Plan 2021, el cual comprendía un conjunto de iniciativas como Compite, Comprendo, Conéctate, Edifica, Edúcame, Juega Leyendo, Megatec, Poder, Redes y Todos Iguales que abordaban aspectos relacionados con inglés, lectura, matemática, tecnología, infraestructura, promoción integral de la juventud, etc. Todos estos programas dieron paso a los incrementos de cobertura territorial mencionados anteriormente.

En la actualidad, el Ministerio de Educación sigue implementando iniciativas emblemáticas que buscan mejorar los indicadores de educación, tales como el Programa de Plan Nacional de Formación de Docentes en Servicio del Sector Público, elPrograma de Paquetes Escolares que se amplió a bachillerato y equipa de forma gratuita a los estudiantes con insumos básicos para su asistencia a la escuela, y el Programa "Una Niña, Un Niño, Una Computadora", que provee de computadoras a los estudiantes de las escuelas públicas.

Fuente: Ministerio de Educación de El Salvador. 
los límites superiores pasa de 48 a 70, principalmente en la zona norte del país, así como en los extremos occidentales y orientales, en especial en algunos territorios de La Unión y Santa Ana. (Véase gráfico 8.)

En cuanto al acceso a teléfono, las oportunidades son claramente distintas respecto a 1992. El IOH pasa de cero a veintiséis en 2007, reflejado en un progreso generalizado, que perdió intensidad en la zona costera occidental del país. La particularidad de este servicio es que, al mismo tiempo, ha pasado a ser una parte importante del presupuesto de las familias salvadoreñas, tanto en la modalidad de telefonía fija como móvil. El recuadro 2 contiene un resumen de la evolución de las telecomunicaciones en El Salvador.

Otro esfuerzo notable son las oportunidades generadas en el acceso a la energía eléctrica (ver recuadro 3), en especial en las franjas central y norte de El Salvador, con excepción de algunos territorios uni-municipales de Morazán y el norte de La Unión. La zona costera ha experimentado un progreso pausado que conserva negativamente la zona de exclusión de la costa occidental.

Estos efectos son producto de los aumentos en cobertura asociados con la decisión privada, que guarda relación con un nivel elevado de transferencias corrientes que entran al país anualmente 6 (cerca del 16 por ciento del PIB); que conllevó a una disminución de la distancia en los hogares de los niños en los territorios, aumentando su probabilidad de acceder a la ventaja (véase anexo 7).

Sin embargo, hay territorios con exclusiones comunes en electricidad, refrigerador y teléfono, los cuales siguen estando rezagados como lo estuvieron en 1992. Dichos territorios están ubicados en los departamentos de Morazán, como Cacaopera; Ahuachapán, como Guaymango y San Pedro Puxtla; en San Miguel, como San Antonio; y en Sonsonate, como Santa Catarina Masahuat. Estos territorios urgen de compensaciones para aminorar los desfases respecto a las oportunidades que tienen otros niños en territorios con mayor $\mathrm{IOH}$ en este tipo de infraestructura.

Otros aspectos fundamentales para el desarrollo de los niños son las condiciones de la habitación donde desarrollan sus capacidades. Entre estas se puede mencionar la materialidad de la vivienda, elemento que presenta derivaciones importantes que trascienden en otros aspectos del desarrollo, tal como se mencionó.

En el gráfico 9 se observa un progreso generalizado en torno a los cambios de la materialidad de la vivienda. El valor mínimo del $\mathrm{IOH}$ referido a esta ventaja pasa de 3.8 a 9.7 puntos; así como el límite superior, que pasa de 81.7 a 90.6 .

Los ejemplos emblemáticos del progreso en este rubro son algunos territorios de Chalatenango, como San Isidro Labrador Las Flores, Las Vueltas, San Antonio Los Ranchos y Nueva Trinidad; de La Paz, con Jerusalén y Mercedes La Ceiba; de Morazán, como Meanguera; y de Usulután, como California, los cuales muestran cambios en el $\mathrm{IOH}$ de materialidad mayores a 50 unidades.

En paralelo, el hacinamiento en los hogares es otro aspecto fundamental del entorno de los niños. Los hogares no hacinados presentan una mejora notoria en el límite superior, pasando de 29 unidades de $\mathrm{IOH}$ en 1992 a 49 en 2007. Las condiciones de hacinamiento se reducen sobre todo en la franja central del país, y se conservan algunos territorios uni-municipales en zonas de Morazán y el norte de la Unión en el límite inferior de la distribución, así como un retroceso en algunos hogares de Ahuachapán.

Finalmente la cobertura y la menor distancia de la materialidad de la vivienda pueden explicar de mejor manera los movimientos del IOH en paralelo. No así en el caso de Hogares no Hacinados, donde claramente se determinan por la cobertura, más que por la reducción en la distancia. (Véase anexo 8.) El detalle de los $\mathrm{IOH}$ estimados y sus respectivos componentes se encuentran disponibles en el anexo 9.

\section{La descomposición de Shapley. Modelos comparados en el tiempo}

Este apartado busca responder a las preguntas dos y tres de la investigación sobre cuál es el peso del territorio en comparación con las circunstancias personales que explican la inequitativa distribución de las oportunidades, y en paralelo abordar la importancia del territorio en dicha distribución.

\footnotetext{
6 Según los V Censos de Población y IV de Vivienda de El Salvador, los hogares que reciben con mayor frecuencia las remesas familiares son los que residen en el departamento de La Unión como Bolívar, Concepción Oriente, Meanguera del Golfo y Pasaquina; Santa Ana, como San Antonio Pajonal, Santa Rosa Guachipilín; y Chalatenango, con Agua Caliente, El Carrizal y Nombre de Jesús. Dichos territorios comparten IOH en los extremos superiores en algunas de las categorías evaluadas.
} 
Gráfico 7. $1 \mathrm{OH}$ en Acceso a Escolaridad a Tiempo 1992 y 2007 por Territorio Funcional de El Salvador
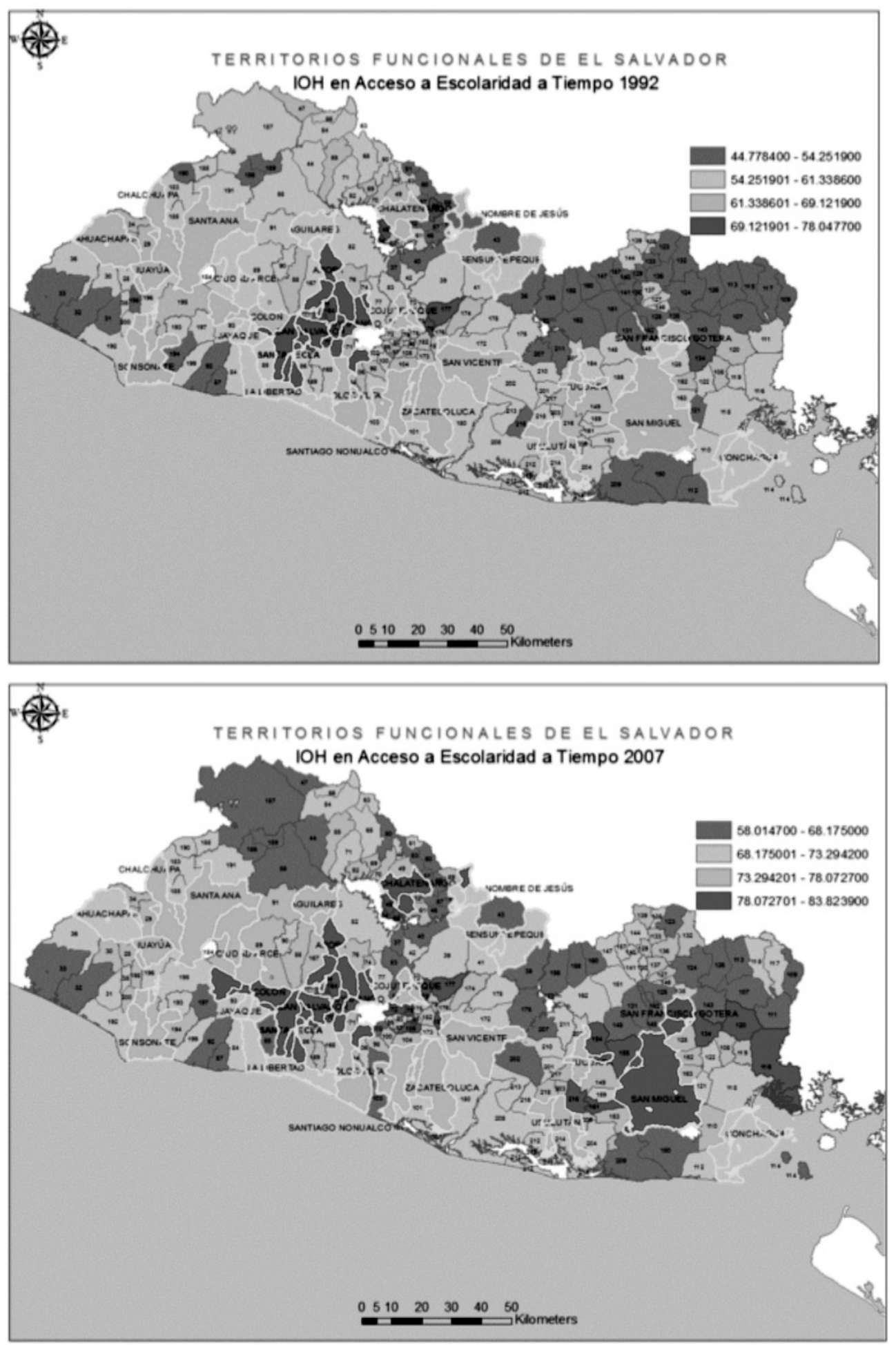

Fuente: Elaboración propia con base en IV Censos de Población y III de Vivienda de El Salvador del año 1992 y de los V Censos de Población y IV de Vivienda de El Salvador del año 2007. 
Gráfico 8. IOH en Acceso a Refrigerador, Teléfono y Electricidad 1992 y 2007 por Territorio Funcional de El Salvador
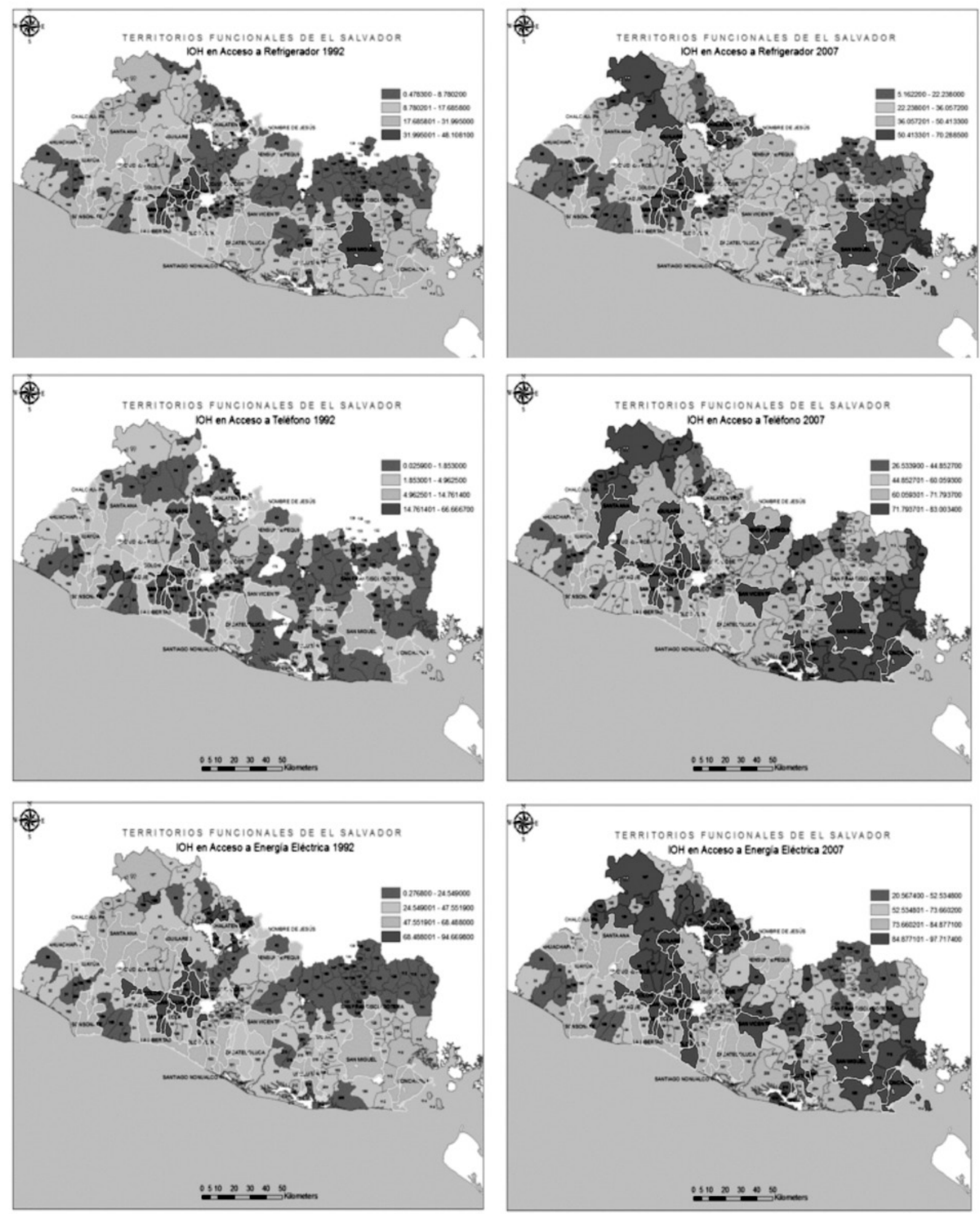

Fuente: Elaboración propia con base en IV Censos de Población y III de Vivienda de El Salvador del año 1992 y de los V Censos de Población y IV de Vivienda de El Salvador del año 2007. 
Recuadro 2. Evolución de las Telecomunicaciones en El Salvador

El sector de telecomunicaciones fue afectado por las reformas neoliberales impulsadas en la década de los 90 , cuando inició un proceso de privatización de las telecomunicaciones, ocasionando el paso a manos privadas la empresa estatal, Antel.

La privatización se dio en paralelo a la creación de la institucionalidad. En 1996, la Asamblea Legislativa aprobó la Ley de Creación de la Superintendencia General de Electricidad y Telecomunicaciones (Siget), la cual tenía las funciones de contraloría del sector, así como la primera Ley de Telecomunicaciones, que posteriormente fue derogada y sustituida, en el año 1997, por la actual.

En 1998 se aprueba la Ley de Privatización del operador público y la Ley de Establecimiento del Fondo Nacional de Inversión en Electricidad y Telecomunicaciones. Este nuevo esquema regulatorio fomentó la regulación mínima y cambió la modalidad de operación que implicaba la búsqueda de la concesión del servicio público de telefonía y del espectro radioeléctrico.

La privatización dio origen a dos empresas: una que se encargaría de operar el servicio alámbrico (CTE-Antel), y la otra, el servicio inalámbrico de telecomunicaciones (Intel). En 1998, France Telecom compró el 51 \% de las acciones de CTE-Antel, dejando el resto de las acciones en manos del Gobierno, de los trabajadores y pensionados. Por otra parte, Telefónica de España se convirtió en el socio mayoritario de Intel. En años siguientes CTE-Antel fue adquirida por América Móvil de México. Todo esto fomentó la cobertura como producto de la dinámica del mercado. En 2010, se fortaleció la regulación del sistema orientada al consumidor, Siget inició con el establecimiento del valor máximo de las tarifas básicas del servicio de telefonía fija y móvil.

Fuente: Siget.

Recuadro 3. Evolución del sector electricidad en El Salvador

A mediados de los años 90, se impulsó el Programa de "Asistencia Técnica al Sector de Energía Eléctrica", el cual formaba parte de un proceso de reforma del sector eléctrico. El primer paso consistió en la aprobación en 1996 de la Ley General de Electricidad y la Ley de Creación de la Siget, que también tenía funciones de regulación y supervisión para el sector eléctrico.

Posteriormente, se realizó la privatización de las generadoras térmicas con base en derivados del petróleo y de las empresas distribuidoras de energía eléctrica que hasta entonces se encontraban en poder de la Comisión Ejecutiva Hidroeléctrica del Río Lempa propiedaddel Estado.

En 1998 se creó la Empresa Transmisora de El Salvador y la Unidad de Transacciones, la cual es la entidad responsable de operar y administrar el sistema eléctrico. Entre 1999 y 2010, se realizaron reformas para cambiar el funcionamiento del mercado basado en oferta de precios, con el objetivo de tener mayor transparencia y apertura a un mercado de contratos de largo plazo.

Entre 2003 y 2008 se realizan varias reformas a la Ley General de Electricidad, junto con la aprobación de la Ley de Creación del Consejo Nacional de Energía (CNE), el cual funge como ente rector de la política energética.

Producto de la política energética, se aprueba una nueva normativa para el fomento de la producción de energías renovables, Ley de Incentivos Fiscales para las Energía Proveniente de Fuentes Renovables No Convencionales; y en 2011 se estableció un nuevo esquema de operación del mercado mayorista, que busca mejorar la formación de precios en el mercado.

Fuente: CNE 
Gráfico 9. $1 \mathrm{OH}$ en Acceso a Materialidad de la Vivienda y Hogar no Hacinado 1992 y 2007 por Territorio Funcional de El Salvador
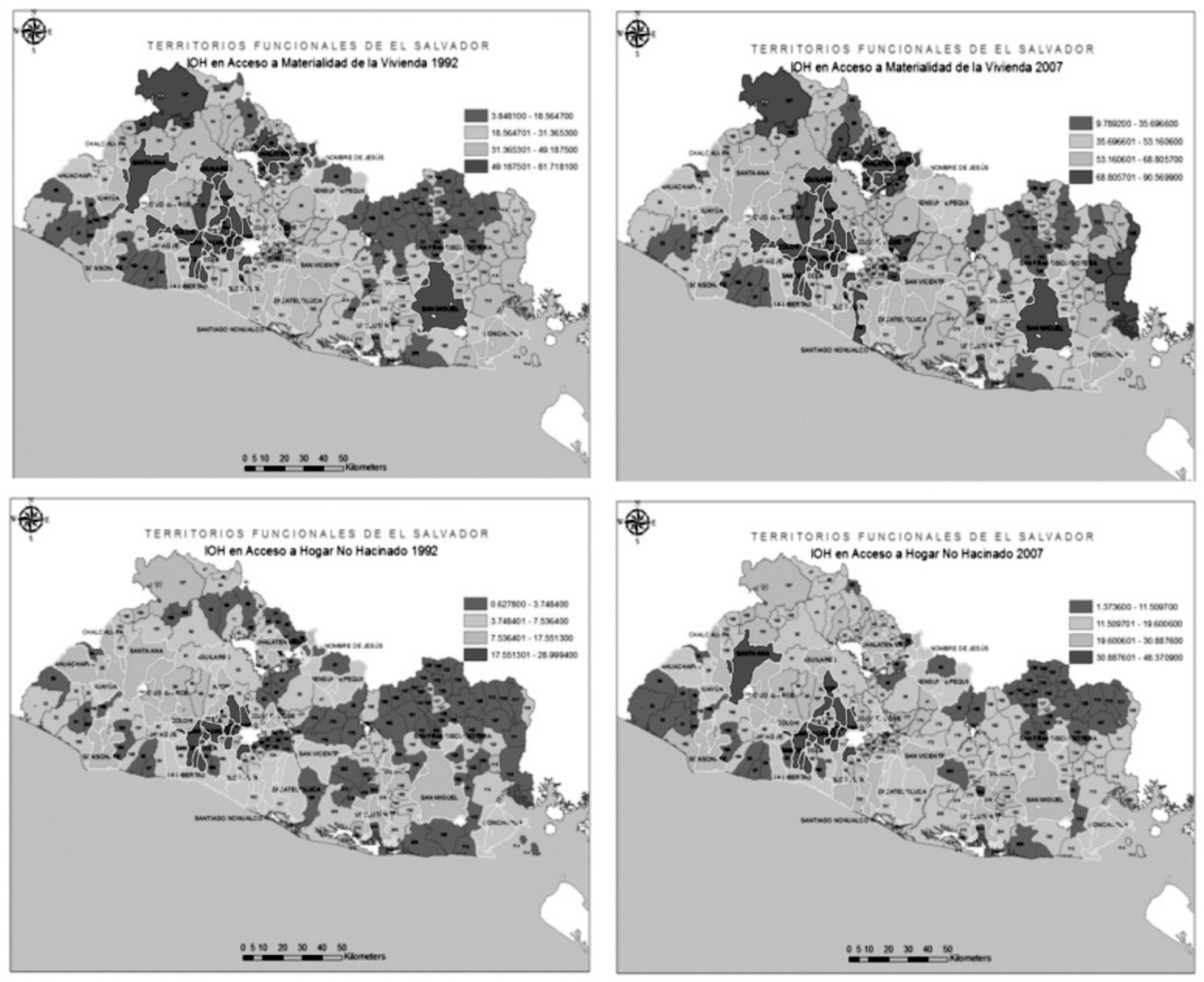

Fuente: Elaboración propia con base en IV Censos de Población y III de Vivienda de El Salvador del año 1992 y de los V Censos de Población y IV de Vivienda de El Salvador del año 2007.

Para responder a estas preguntas se realizó una nueva estimación del $\mathrm{IOH}$, donde se utilizaron las mismas circunstancias definidas para la estimación territorial anterior, agregando circunstancias con características territoriales que por su naturaleza son compartidas por la mayoría de los hogares de cada territorio funcional y que afectan las oportunidades de los niños.

La estrategia consistió en comparar las contribuciones de las circunstancias para determinar la forma en que cambian en el tiempo, así como evaluar el significado de la importancia de cada circunstancia en la determinación de las oportunidades. Por lo tanto, se calcularon IOH para los años 1992 y 2007, así como su respectiva descomposición de Shapley.

La descomposición sigue lo recomendado por Soloaga y Chávez (2010), citado en Tomaselli, A. (2014) y Hoyos y Narrayan (2012), donde el componente de inequidad expresado por el índice de disimilitud -la desigualdad "D" obtenida en el cálculo del $\mathrm{IOH}$ - puede sujetarse a una descomposición Shorrocks- 
Shapley, de 1999, con el objetivo de determinar el aporte de cada circunstancia en la inequidad total.

El principio básico de la propuesta descansa en aislar el impacto que tiene la incorporación de una circunstancia adicional en la especificación de la regresión logística estimada para calcular la inequidad; sin embargo, dado que existe una correlación entre las circunstancias nuevas y las incorporadas anteriormente dentro del modelo, es necesario considerar las relaciones de dicha circunstancia adicional con respecto a todos los subconjuntos posibles de circunstancias anteriormente incorporados, de tal forma que se aíslen los efectos individuales, así:

$$
D_{A}=\sum_{s \subseteq n \mid\{A\}} \frac{|s| !(n-|s|-1) !}{n !}[D(S \cup\{A\}-D(S)]
$$

Donde $n$ corresponde al set de todas las circunstancias existentes, $s$ es un subconjunto de circunstancias que excluye a la circunstancia $A . D(S)$ corresponde al índice de disimilitud estimado con el set de circunstancias $s$ y $D(S \cup\{A\}$ es el índice de disimilitud estimado con el set de circunstancias $s$ y la circunstancia $A$.

Así se puede definir el aporte de la circunstancia $A$ al índice de

$$
M_{A}=\frac{D_{A}}{D(n)} ; \text { donde } \sum_{i \in n} M_{i}=1
$$

disimilitud como:

Las circunstancias personales utilizadas en este ejercicio son las mismas calculadas en el capítulo II, por lo que se construyeron sobre las mismas bases de datos, para el mismo universo de estudio y con la misma división territorial, por lo tanto, las observaciones a la base de datos, mencionadas anteriormente, se mantienen. Adicionalmente se incluyeron variables de tipo territorial calculadas a partir de los promedios

\begin{tabular}{|c|c|c|c|}
\hline PA15AM & $\begin{array}{l}\% \text { población analfabeta } 15 \\
\text { años o mas }\end{array}$ & Numérica & $\begin{array}{c}\text { Elaboración propia con base en IV Censos de } \\
\text { Población y III de Vivienda de El Salvador del año } \\
1992 \text { y de los V Censos de Población y IV de Vivienda } \\
\text { de El Salvador del año } 2007\end{array}$ \\
\hline CAPITAL & $\begin{array}{l}\text { Dummy Capital } \\
\text { estatal/regional/provincial }\end{array}$ & $\begin{array}{l}\text { Dicotómica, } 1 \text { cuando hay el TF incorpora a los municipios } \\
\text { de San Salvador, Santa Ana o San Miguel; 0, en otro caso. }\end{array}$ & \\
\hline AMAR & Región natural / clima & $\begin{array}{c}\text { Dicotómica, Se aproximó con identificar aquellos } \\
\text { municipios costeros (con acceso a mar), la variable toma } \\
\text { valor } 1 \text { y } 0 \text {, en otro caso. }\end{array}$ & \\
\hline DP & Densidad Poblacional & Numérica & $\begin{array}{l}\text { IV Censos de Población y III de Vivienda de El } \\
\text { Salvador del año 1992; Atlas Sociodemográfico } 2007 .\end{array}$ \\
\hline $\begin{array}{l}\text { TFU, TFUAR, } \\
\text { TFUBR, TFR }\end{array}$ & $\begin{array}{l}\text { Clasificación de ruralidad } \\
\text { según TF de Amaya y Cabrera } \\
\text { (2012) }\end{array}$ & $\begin{array}{l}\text { En este caso son } 4 \text { variables dicotómicas que se activan } \\
\text { cuando el territorio pertenece a la categoría. Urbano, } \\
\text { Urbano Alto-rural, Urbano bajo-rural y Rural }\end{array}$ & Amaya y Cabrera (2012) \\
\hline
\end{tabular}

Cuadro 3. Circunstancias adicionales utilizadas para la estimación del $1 \mathrm{OH}^{7}$

Elaboración propia con base en Tomaselli 2014.

7 Según Amaya y Cabrera 2012, un territorio funcional se clasifica como Rural debido a que cuentan con un centro urbano cuyo nivel de urbanización es menor o igual al $25 \%$, los Urbano bajo-rural cuyo nivel de urbanización del centro está por arriba del $25 \%$ pero es menor o igual al 50 \%, los Urbano altos-rural con niveles superiores al 50 \% pero inferiores o iguales a 75 \% y los completamente Urbanos referidos a aquellos cuyo centro urbano cuenta con un nivel de urbanización superior al $75 \%$. 
Gráfico 10. Porcentaje de explicación de las variables personales versus las territoriales

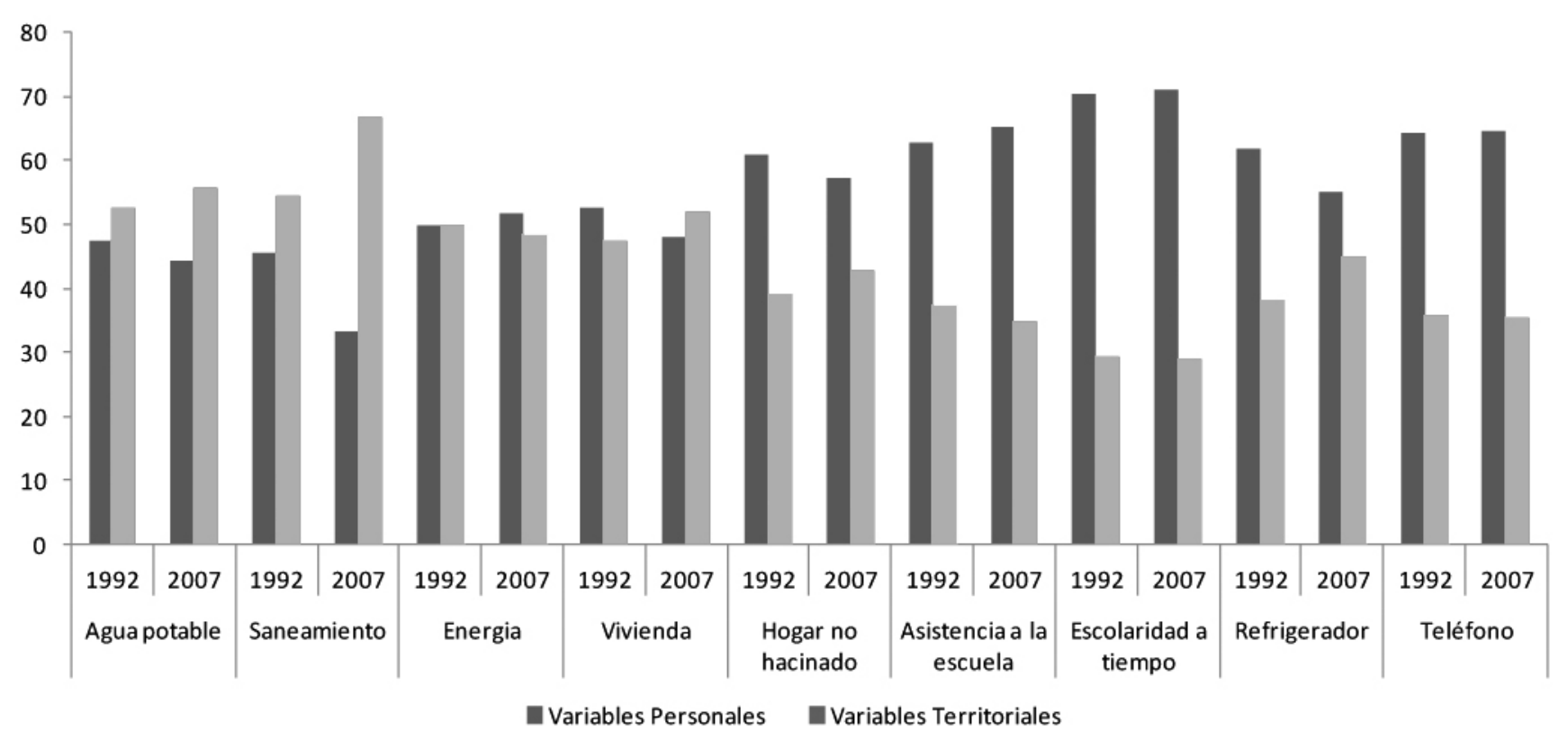

Fuente: Elaboración propia con base en IV Censos de Población y III de Vivienda de El Salvador del año 1992 y de los V Censos de Población y IV de Vivienda de El Salvador del año 2007.

de los territorios funcionales, que se enumeran en el cuadro 3. El análisis de la descomposición por circunstancia revela que, en los dos años referenciados, el orden de las circunstancias que explican con mayor fuerza las desigualdades en el acceso a las ventajas son siempre las circunstancias personales, que incluye aquellas aplicables al contexto del hábitat específico del niño a nivel de hogar, tales como el sexo del menor, el del jefe de hogar, la educación y la ocupación de este, y si el hogar es monoparental o no, las cuales sobresalen por las circunstancias definidas a nivel territorial (véase el cuadro 4).

No obstante, al agrupar las circunstancias territoriales, evidencian ser más importantes que las variables personales en la explicación del acceso a ciertas ventajas como el agua potable, el saneamiento y la vivienda adecuada; o, en su defecto, se acercan mucho al poder explicativo de las variables personales, tal como el acceso a energía eléctrica.

La relevancia de este hallazgo se enmarca dentro de la concepción territorial de las desigualdades; al existir algunas ventajas básicas que aún dependen del lugar de residencia de los niños, la solución se vuelve una competencia de la planificación territorial, permitiendo fundamentar las oportunidades desde el marco de las políticas púbicas, con el objetivo de acortar las brechas en las desigualdades.

En términos de su evolución en el tiempo, las circunstancias personales tienden a disminuir su peso o experimentan una leve variación en su nivel de explicación en la mayoría de las oportunidades de 2007 respecto a los resultados de 1992 (ver gráfico 10).

Una explicación viable para esto último es la reducción de la pobreza experimentada entre los años 1992 y 2007 (10 puntos porcentuales en los últimos 10 años previos a 2007), que permitió que las características específicas del hogar pierdan peso en la definición del acceso a dichas ventajas y desplazando su poder explicativo a las variables territoriales.

Así, cuando un hogar deja de ser pobre, en el sentido monetario, tiene una mayor probabilidad de construir una vivienda más amplia, con cañería para el suministro del agua potable, implementar un sistema adecuado para el manejo de las aguas residuales o comprar un refrigerador o un teléfono; 


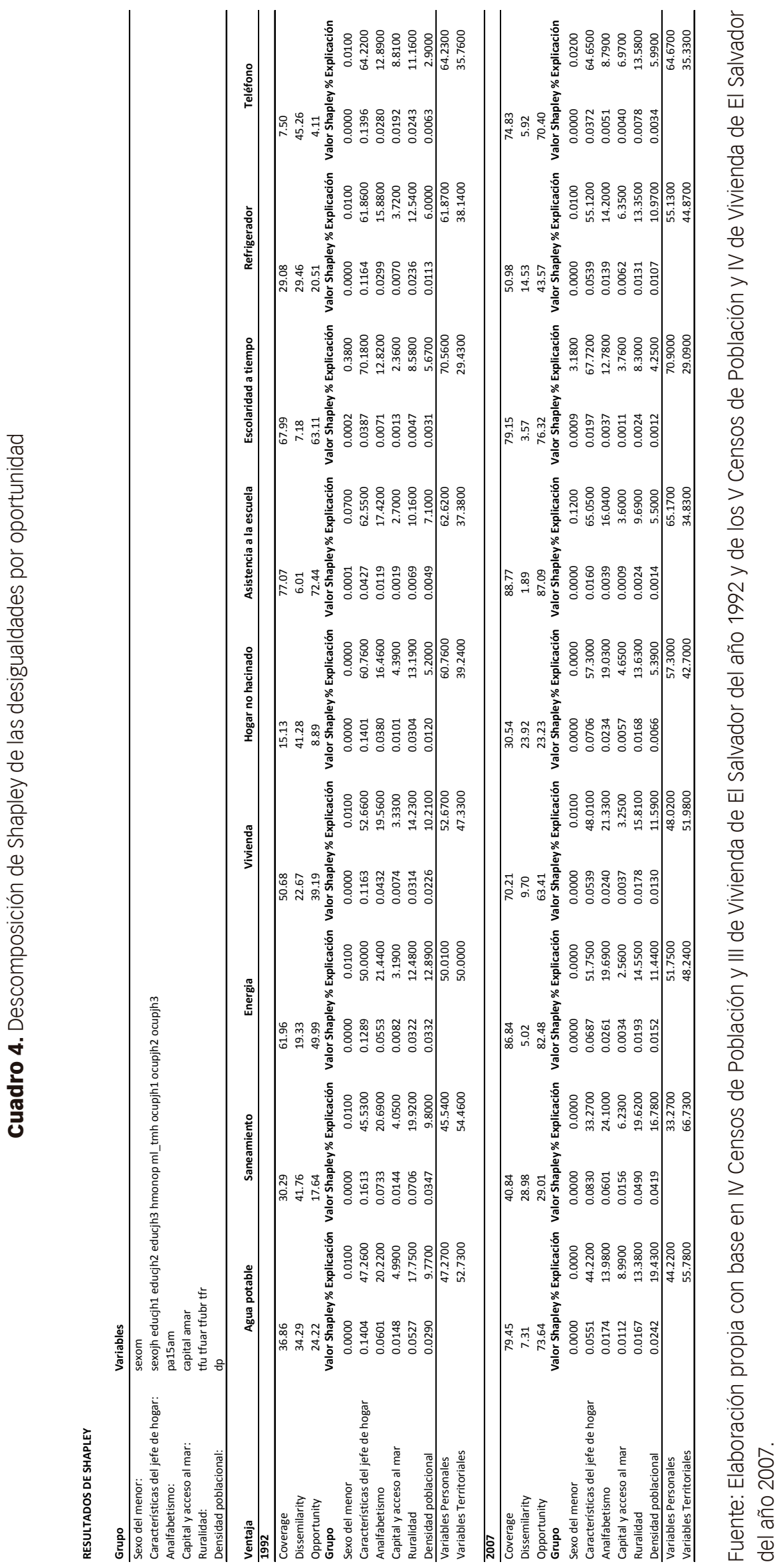


mientras que un hogar en situación de pobreza enfrenta restricciones para su manutención básica, lo que disminuye las probabilidades para el acceso a las ventajas mencionadas.

De esta forma, son las características territoriales las que aumentan la explicación en promedio 5 puntos porcentuales en dichas oportunidades, haciendo que estas dependan de la ubicación de la residencia del niño o la niña, en circunstancias como ruralidad del territorio, nivel de analfabetismo o si reside en las principales ciudades.

Esta tendencia territorial es de suma importancia, pues lo que indica es que la disminución de las desigualdades en estas ventajas puede ser corregida mediante la inversión pública en los territorios, de tal forma que se reorienten las oportunidades y disipe las desigualdades, tal como se mencionara.

Las tres únicas ventajas donde se reflejan aumentos claros del porcentaje de explicación de las circunstancias personales son en el acceso a energía eléctrica, la asistencia a la escuela y la escolaridad a tiempo. En estos ítems hay un aspecto común relacionado con la menor desigualdad, derivada de los mayores incrementos de cobertura (ver gráfico 11). Dichos incrementos habrían disminuido las brechas territoriales y por tanto las distancias de acceso, aportando más peso a las circunstancias personales.
Particularmente, las ventajas relacionadas con la educación se vieron intensificadas por los esfuerzos gubernamentales y con los incrementos en escolaridad de la población, ${ }^{8}$ ya que dichos incrementos se relacionan directamente con una mayor conciencia del jefe de hogar educado respecto a la importancia que tiene la inversión en los niños (Guryan, J. et al., 2008). De tal manera que son los jefes de hogar más educados los que visualizan a la educación como medio para lograr un mejor futuro de sus hijos y de su familia.

No obstante, la escolaridad a tiempo plantea un reto a nivel de hogar, tanto desde la perspectiva de un mayor ingreso como de la concienciación de la importancia de cumplir con el programa de estudios en el tiempo definido, ya que las circunstancias personales siguen teniendo prácticamente el mismo nivel de explicación con un pequeño incremento en el año 2007.

Dentro de las circunstancias personales, destaca la pérdida del poder explicativo del sexo del menor o su estabilidad en un valor muy bajo (0,01-0,02 \%) en la determinación de las ventajas de infraestructura y equipamiento como agua, saneamiento, energía, vivienda, hacinamiento, refrigerador y teléfono entre los años 2007 y 1992, implicando que el menor tiene acceso a estas oportunidades, independientemente de su sexo.

Gráfico 11. Desigualdad y Cobertura de los IOH de Energía Eléctrica, Asistencia a la Escuela y Escolaridad a Tiempo
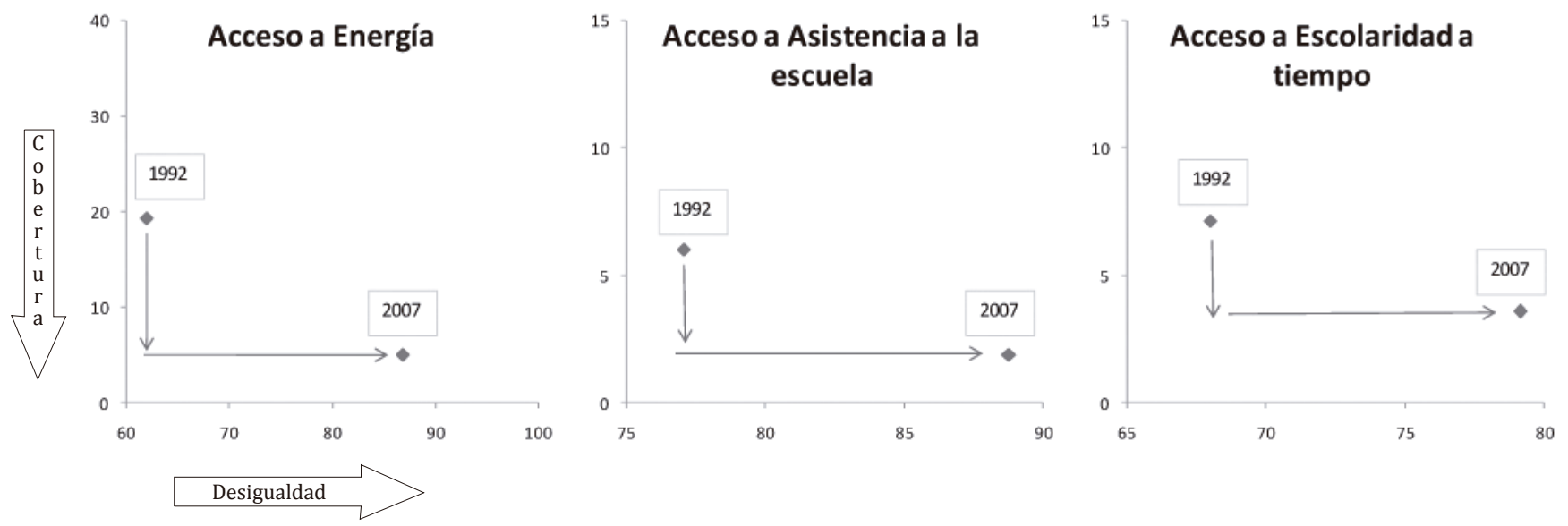

Fuente: Elaboración propia con base en IV Censos de Población y III de Vivienda de El Salvador del año 1992 y de los V Censos de Población y IV de Vivienda de El Salvador del año 2007.

8 Según EHPM, el porcentaje de personas de seis años y más que reportan no tener algún año de estudio aprobado se redujo en 4.8 puntos porcentuales en los 10 años previos a los censos de 2007 . 
Gráfico 12. Desigualdad y Cobertura de los IOH de Acceso a Vivienda Adecuada y a Teléfono
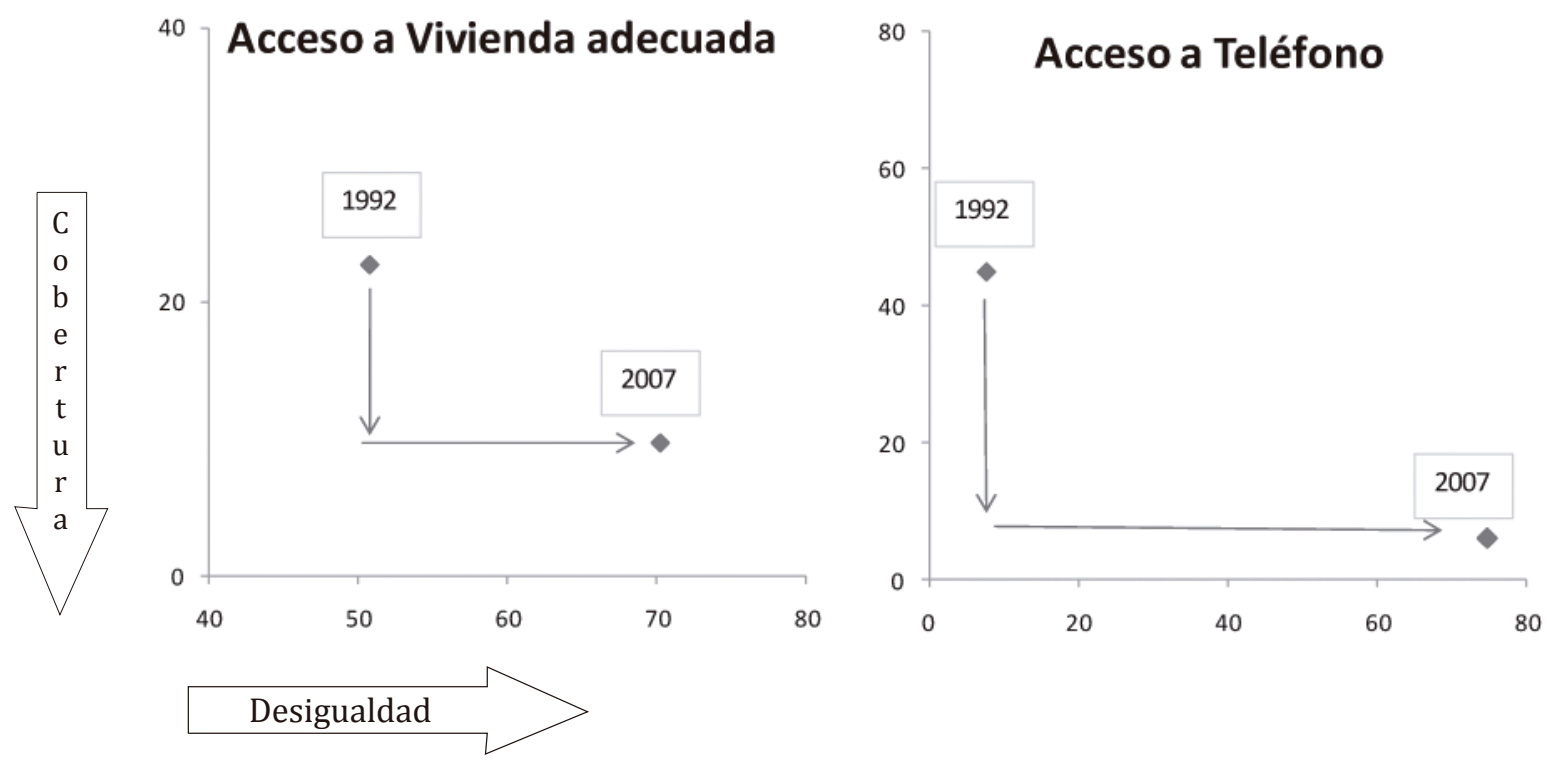

Fuente: Elaboración propia con base en IV Censos de Población y III de Vivienda de El Salvador del año 1992 y de los V censos de Población y IV de Vivienda de El Salvador del año 2007.

Noasícuando seabordan lasventajas deasistenciay escolaridad a tiempo. Dichos resultados se perciben preocupantes a primera vista. La importancia que tiene el sexo del niño en el acceso a educación tiende a aumentar entre ambos años, siendo más alto en el 2007 respecto a lo que explicaba en el 1992. Esto sugiere que el sexo del menor es un determinante importante para el acceso a la educación, incrementando la desigualdad. Sin embargo, las estadísticas nacionales de EHPM desvirtúan esta suposición; la participación de las niñas que asisten a la escuela entre 4 a 15 años ha incrementado en casi 11 puntos porcentuales en los 10 últimos años previos a 2007, indicando un progreso importante en el acceso a educación de las niñas que contrasta con los resultados de la descomposición de Shapley.

Otra posible explicación a los resultados, que hace sentido con la evidencia de las estadísticas nacionales, es que los esfuerzos de cobertura territorial en los aspectos educativos disminuyeron el nivel de desigualdad, bajándole peso al resto de explicativos que volcaron su participación sobre las discrepancias del sexo. Este cambio descubrió problemas no visibles anteriormente que, a pesar del progreso en la equidad de género en la educación, hoy se pueden apreciar mejor porque otras características ya no son tan relevantes en la determinación de la desigualdad. Esto no precisa necesariamente un deterioro en la desigualdad de acceso a
Gráfico 13. Desigualdad y cobertura de los $\mathrm{IOH}$
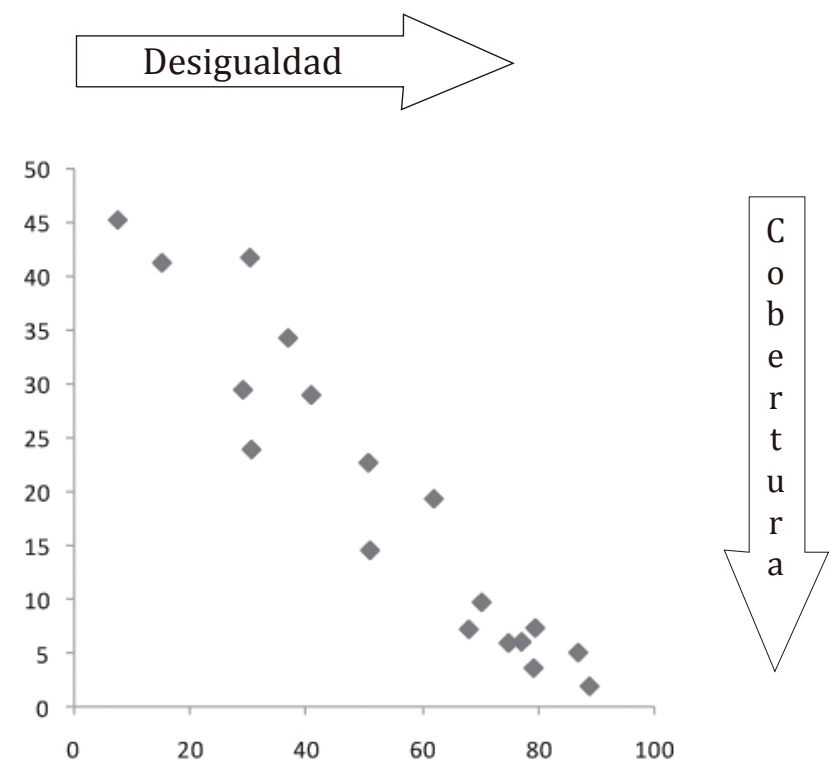

Fuente: Elaboración propia con base en IV Censos de Población y III de Vivienda de El Salvador del año 1992 y de los V Censos de Población y IV de Vivienda de El Salvador del año 2007. 
educación de las niñas, pero sí pone en perspectiva nuevas prioridades que se deben atender.

En cuanto a las variables territoriales, se observa que la población analfabeta de 15 años o más, incorporada para aproximar la capacidad que tiene la población de absorber nuevas tecnologías y de realizar trabajos más complejos, perdió poder de explicación en la mayoría de ventajas. Por el contrario, el peso tiende a incrementar en las ventajas de saneamiento, materialidad de la vivienda y hacinamiento, lo que está muy relacionado con una menor capacidad de generación de ingresos en el territorio, consistentes con una población analfabeta.

Estar en la capital, en una ciudad importante del país o tener acceso al mar, tiende a explicar en mayor medida las desigualdades en 2007 que en 1992, en la mayoría de ventajas. Esto está en línea con una zona costera de menores IOH vista en el capítulo II, que se superpone a la menor desigualdad de las principales ciudades.

No obstante, en ventajas como el acceso a energía, a vivienda adecuada y a teléfono, se tiene un menor nivel de explicación de estas variables que en 1992. Este resultado está en línea con todos los esfuerzos de cobertura, los que se encuentran más distribuidos en el territorio. (Véase gráfico 12.)

El nivel de ruralidad del territorio en 2007 sigue siendo importante o incrementa su capacidad de explicación en el acceso a saneamiento, energía, a la vivienda, el hacinamiento, el acceso a refrigerador y al teléfono, sin embargo, disminuye en el resto de accesos a ventajas. Esto es importante porque delimita la influencia de la ruralidad de los territorios a aspectos puramente de infraestructura y no a los temas de inclusión personal como la educación. Esta separación es positiva en términos que revela el esfuerzo educativo de las políticas públicas mencionado anteriormente, pero a la vez permite una mejor orientación para los tomadores de decisión, al considerar que las oportunidades se potencian cuando las inversiones de formación de capital en infraestructura básica en áreas rurales se aumentan.

Otro elemento importante es que los resultados evidencian una clara correlación negativa entre los aumentos de cobertura y la disminución de la desigualdad. El gráfico 13 muestra los niveles de cobertura en el eje de las $x$ y la desigualdad en el eje de las y. Este tipo de correlación desvela que los esfuerzos de las políticas públicas por lograr incrementos de cobertura generalmente tienen consecuencias positivas en la reducción de la desigualdad.

\section{Conclusiones}

Es evidente que la distribución de las oportunidades de desarrollo de los niños y jóvenes en el país está muy correlacionada con la distribución de la pobreza evaluada desde la perspectiva de las restricciones múltiples.

A pesar de que se observan avances territoriales importantes en términos de oportunidades, todavía se conservan algunos patrones territoriales significativos. La franja central de El Salvador, identificada por el corredor de las principales ciudades, Santa Ana, San Salvador, la parte norte de La Libertad y San Miguel, evidencian tener mejores oportunidades de desarrollo que el resto del país. Las franjas norte y sur poseen territorios rezagados con niveles de $\mathrm{IOH}$ en el límite inferior de la distribución. Entre el norte y el sur de El Salvador, las oportunidades son mayores en el sur (costero) que en el norte (montañoso).

Así mismo, se destaca que los municipios más interconectados, menos pobres multidimensionales, con menor ruralidad y en algunos casos con menor vulnerabilidad socioeconómica ante el cambio climático, como los cercanos a la capital, San Salvador, son los que han mantenido o mejorado su estatus de oportunidad; mientras que los territorios menos urbanos, con menor conectividad y mayor pobreza multidimensional, como los territorios del norte de San Miguel, algunos de Morazán, Ahuachapán y Sonsonate presentan evidentes carencias que definen la baja oportunidad de sus niños y jóvenes.

En este último grupo se identifican territorios donde los niños han estado históricamente condenados a la pobreza, marcados por la falta de oportunidades crónica; estos territorios se ubican históricamente en la cota inferior de la distribución. Algunos ejemplos son los pertenecientes al departamento de Morazán, como Torola, San Fernando, Yamabal, Cacaopera, Gualococti; al departamento de Sonsonate, como Cuisnahuat y Santa Isabel Ishuatán; Concepción de Ataco, en Ahuachapán, y Panchimalco, en San Salvador; de ahí que la capitalización de estos territorios es la clave, con miras a un cambio estructural que permita el empleo suficiente para la reducción de la pobreza en dichos territorios y contribuya a la distribución equitativa de las oportunidades.

Respecto a los determinantes de las desigualdades, se demostró que el contexto específico del niño en el hogar sigue siendo más importante para la determinación de la probabilidad de acceder a las oportunidades, que las 
características territoriales comunes a los habitantes del territorio, con excepción de las ventajas como el agua potable, el saneamiento y la vivienda.

Sin embargo, se destaca que las circunstancias personales han tendido a disminuir su capacidad de explicación en el tiempo en la mayoría de oportunidades, dando lugar a un mayor poder explicativo de las variables territoriales. Esta tendencia territorial es de suma importancia, pues lo que indica es que la disminución de las desigualdades puede ser corregida mediante la inversión pública en los territorios, de tal forma que se reorienten las oportunidades y se disipen las desigualdades.

Particularmente, se destacan los esfuerzos realizados en la mayor cobertura de las ventajas relacionadas con la educación, las cuales se vieron intensificadas por los esfuerzos gubernamentales y en especial por la influencia positiva que tiene la educación de los jefes de hogar como medio multiplicativo en la ampliación de las oportunidades de sus hijos.

Finalmente, otro elemento importante resultado de este trabajo son las recomendaciones para la formulación de las políticas públicas territoriales, las cuales deben considerar que, en la mayoría de los casos, los intentos por una mayor cobertura van acompañados de una menor desigualdad. Por lo tanto, la capitalización agresiva de los territorios menos afortunados tiene sentido en cuanto que en paralelo se disminuyen también las distancias en el acceso a las oportunidades.

Algunos ejemplos de políticas públicas son detallados por Barros, et al. (2008), cuyo aporte es retomado a continuación debido a que se consideran relevantes para la orientación de la política pública en El Salvador.

Uno de estos ejemplos es el caso de Brasil, donde se articularon tres esfuerzos concretos para lograr una serie de metas identificadas, que consistían en la reducción de la repitencia escolar y las deficiencias de aprendizaje. La primera medida estuvo orientada a mejorar la disponibilidad y calidad de los insumos escolares, para el correcto desempeño de las labores educativas; la segunda, orientada a atacar directamente la repitencia; y la tercera, con el objetivo de ejecutar transferencias monetarias para brindar incentivos a los jefes de hogar, para que continuaran enviando a sus hijos a la escuela.

Otro ejemplo mencionado en la misma publicación y de interés para El Salvador es el caso del acceso al agua en Paraguay y las asociaciones de usuarios de aguas "juntas". Dichas organizaciones son conformadas con la participación de las comunidades interesadas en desarrollar los proyectos de acceso al agua, las que aportan en efectivo o en especie los insumos necesarios para su implementación y son asesoradas técnicamente en paralelo por el gobierno. Estas juntas también administran los accesos al agua y han tenido mucho éxito en el país para mejorar la cobertura del agua, especialmente en área rural.

Un caso más ambicioso, pero que evidencia claramente la importancia de contar con mediciones de oportunidad para los territorios, es el caso chileno de "Chile Crece Contigo". Este es un programa gubernamental de transferencias destinado a proveer de servicios básicos a los niños en situación de pobreza, a partir de la lógica de las oportunidades humanas para corregir de forma temprana y sistemática las deficiencias que potencialmente limitarán el desarrollo de los niños.

Ahora bien, en un país con poco margen para la maniobra fiscal como El Salvador, el financiamiento de este tipo de programas es un problema. Sin embargo, en el caso concreto de los esfuerzos educativos, coordinados con una política de transformación estructural, las tasas de retorno pueden ser lo suficientemente atractivas para los acreedores externos, siempre y cuando se garantice la utilización específica y un control estricto del destino de los fondos contratados en este tipo de iniciativas.

\section{Referencias}

Ali, I., \& Zhuang, J. (July, 2007). Inclusive Growth Toward a Prosprerous Asia. (Working Paper N 97). ERD.

Amaya, P., \& Cabrera, O. (2013). Territorios Funcionales en El Salvador. (Documento de Trabajo $N^{\circ}$ 15). Serie Estudios Territoriales. Santiago, Chile: Programa Dinámicas Territoriales Rurales-Rimisp.

Amaya, P. \& Cabrera, O. (2013). La Transformación Estructural: una solución a la trampa de bajo crecimiento económico en El Salvador. (Documento de Trabajo, No. 2013 - 01). San Salvador, El Salvador: Banco Central de Reserva de El Salvador.

Amaya, P. \& Cabrera, O. (2013). Vulnerabilidad Socioeconómica ante el Cambio Climático en El Salvador. (Documento de Trabajo). RIMISP.

Amaya, P. \& Cabrera, O. (2013). Informe de Pobreza Rural en El Salvador. Documento elaborado para RIMISP.

De Barros, R. P., Ferreira, F. H. G., Molinas Vega, J. R., \& Saavedra Chanduvi, J. (2008). Midiendo la Desigualdad de 
Oportunidades en América Latina y el Caribe. Banco Mundial.

De Barros, R.P., Giugale, M., Molinas, J.R., \& Saavedra, J. (2010). Do Our Children Have a Chance? The 2010 Human Opportunity Report for Latin America and the Caribbean. Banco Mundial.

Berdegué, J., Jara, B., Fuentealba, R., Tohá, J., Modrego, F., Schejtman, A., \& Bro, N. (2011). Territorios Funcionales en Chile. (Documento de Trabajo, No. 102). Santiago, Chile: Programa Dinámicas Territoriales Rurales. Santiago-Rimisp.

Dirección General de Estadística y Censos del Ministerio de Economía. Encuestas de Hogares de Propósitos Múltiples. Varios años. San Salvador, El Salvador.

Escobal, J. (2012). Multidimensional Poverty and Inequality of Opportunity in Peru: Taking Adventage of the Longitudinal Dimension of Young Lives. (Working Paper, No.79). Young Lives.

Felipe, J. (2010). Inclusive Growth, Full Employment and Structural Change: Implications and Policies for Developing Asia. London: Anthem Press.

Guryan, J., Hurst, E. \& Kearney, M. (2008). Parental Education and Parental Time with Children. Journal of Economic Perspectives. 22 (3), 23-46.
Hausmann, R. \& Klinger, B. (2007). The Structure of Product space and The Evolution of Comparative Adventage. Working Papers Center For International Development At Harvar University. (146), 1-40.

Hausmann, R., Hwang, J., \& Rodrik D. (2005). What You Export Matters. Working Papers Center For International Development At Harvar University. 1-29.

Hidalgo, C.K.B. (2007). The Product Space Conditions the Development of Nations. Science. (317), 482-487.

Hoyos, A., \& Narayan, A. (2012). Inequality of Opportunities Among Children: How Much Does Gender Matter? Paper for World Development Report 2012. Banco Mundial.

Minsky, H. (2013). Ending Poverty: Jobs, Not Welfare. New York: Levy Economics Institute of Board College. Kindle Edition.

Roemer, J., \& Trannoy, A. (2013). Equality of Opportunity. Cowles Foundation For Research in Economics Yale University.

Tomaselli, A. (2014). Pobreza, Vulnerabilidad y Oportunidades en los Territorios Funcionales chilenos (1992-2002). (Documentos de Trabajo No. 132). Santiago, Chile: Desarrollo con Cohesión Territorial para el DesarrolloRimisp. 


\section{Anexo 1. Comparación de promedios territoriales 2007 y 2013}

Una variable importante, por su relevancia en la definición de la capacidad de compra de los hogares y, por ende, de un conjunto de circunstancias y acceso a infraestructura básica, es la distribución de ingreso per cápita mensual en el territorio. El cuadro 1 muestra que entre los años 2007 y 2013 dicha distribución no ha variado mayoritariamente, ya que 10 de los 14 departamentos del país mantienen su posición relativa respecto al promedio del país de cada año.

Cuadro 1. Comparación entre los ingresos per cápita del año 2007 versus el año 2013

\begin{tabular}{l|c|c|c|c|}
\hline \multirow{2}{*}{\multicolumn{1}{c|}{ Departamento }} & \multicolumn{3}{c|}{ Valor } & \multicolumn{2}{c|}{ Posición } \\
\cline { 2 - 5 } & 2013 & 2007 & 2013 & 2007 \\
\hline Ahuachapán & 98.6 & 92.9 & Abajo del promedio & Abajo del promedio \\
Santa Ana & 130.4 & 111.2 & Arriba del promedio & Arriba del promedio \\
Sonsonate & 125.2 & 120.4 & Abajo del promedio & Arriba del promedio \\
Chalatenango & 119.4 & 89.1 & Abajo del promedio & Abajo del promedio \\
La Libertad & 172.7 & 140.9 & Arriba del promedio & Arriba del promedio \\
San Salvador & 197.0 & 164.3 & Arriba del promedio & Arriba del promedio \\
Cuscatlán & 123.9 & 100.8 & Abajo del promedio & Arriba del promedio \\
La Paz & 118.2 & 84.3 & Abajo del promedio & Abajo del promedio \\
Cabañas & 90.0 & 76.5 & Abajo del promedio & Abajo del promedio \\
San Vicente & 117.6 & 78.5 & Abajo del promedio & Abajo del promedio \\
Usulután & 115.1 & 90.2 & Abajo del promedio & Abajo del promedio \\
San Miguel & 126.3 & 103.4 & Abajo del promedio & Arriba del promedio \\
Morazán & 134.8 & 63.7 & Arriba del promedio & Abajo del promedio \\
La Unión & 115.5 & 92.3 & Abajo del promedio & Abajo del promedio \\
\hline
\end{tabular}

Fuente: EHPM 2007 y 2013.

Otras variables que confirman lo anterior son la tasa de dependencia económica y la distribución de los hogares no pobres, también determinantes de la capacidad de compra de los hogares. Los cuadros 2 y 3 muestran que 11 de los 14 departamentos del país mantienen su posición respecto al promedio del país en ambas distribuciones.

Cuadro 2. Comparación de Tasa de Dependencia Económica, 2007 versus 2013

\begin{tabular}{|l|c|c|c|c|}
\hline \multirow{2}{*}{ Departamen to } & \multicolumn{3}{c|}{ Valor } & \multicolumn{2}{c|}{ Posición } \\
\cline { 2 - 5 } & 2013 & 2007 & 2013 & 2007 \\
\hline Ahuachapán & 1.51 & 1.88 & Abajo del promedio & Arriba del promedio \\
SantaAna & 1.33 & 1.56 & Abajo del promedio & Abajo del promedio \\
Sonsonate & 1.4 & 1.59 & Abajo del promedio & Abajo del promedio \\
Chalatenango & 1.45 & 1.98 & Abajo del promedio & Arriba del promedio \\
La Libertad & 1.32 & 1.53 & Abajo del promedio & Abajo del promedio \\
San Salvador & 1.17 & 1.34 & Abajo del promedio & Abajo del promedio \\
Cuscatlán & 1.44 & 1.65 & Abajo del promedio & Abajo del promedio \\
La Paz & 1.48 & 1.8 & Abajo del promedio & Abajo del promedio \\
Cabañas & 1.99 & 2.32 & Arriba del promedio & Arriba del promedio \\
San Vicente & 1.44 & 2.01 & Abajo del promedio & Arriba del promedio \\
Usulu tán & 1.59 & 1.96 & Arriba del promedio & Arriba del promedio \\
San Miguel & 1.57 & 1.91 & Arriba del promedio & Arriba del promedio \\
Morazán & 1.79 & 2.22 & Arriba del promedio & Arriba del promedio \\
La Unión & 2.01 & 2.09 & Arriba del promedio & Arriba del promedio
\end{tabular}

Fuente: EHPM 2007 y 2013. 
Cuadro 3. Distribución de los hogares no pobres, 2007 versus 2013

\begin{tabular}{l|c|c|cc|}
\hline \multirow{2}{*}{ Departamento } & \multicolumn{2}{c|}{ Valor } & \multicolumn{2}{c|}{ Posición } \\
\cline { 2 - 5 } & 2013 & 2007 & 2013 & 2007 \\
\hline Ahuachapán & 58.6 & 58.4 & Abajo del promedio & Abajo del promedio \\
Santa Ana & 67.8 & 65.6 & Arriba del promedio & Arriba del promedio \\
Sonsonate & 67.7 & 64.9 & Arriba del promedio & Arriba del promedio \\
Chalatenango & 63.2 & 62.4 & Abajo del promedio & Arriba del promedio \\
La Libertad & 73.0 & 68.9 & Arriba del promedio & Arriba del promedio \\
San Salvador & 80.1 & 74.9 & Arriba del promedio & Arriba del promedio \\
Cuscatlán & 67.3 & 62.1 & Arriba del promedio & Arriba del promedio \\
La Paz & 66.8 & 59.0 & Arriba del promedio & Abajo del promedio \\
Cabañas & 55.8 & 46.7 & Abajo del promedio & Abajo del promedio \\
San Vicente & 64.4 & 51.8 & Abajo del promedio & Abajo del promedio \\
Usulután & 61.8 & 57.3 & Abajo del promedio & Abajo del promedio \\
San Miguel & 68.7 & 64.3 & Arriba del promedio & Arriba del promedio \\
Morazán & 57.4 & 43.7 & Abajo del promedio & Abajo del promedio \\
La Unión & 68.4 & 59.4 & Arriba del promedio & Abajo del promedio \\
\hline
\end{tabular}

Fuente: EHPM 2007 y 2013.

De forma complementaria se pueden evaluar otros aspectos relacionados con el entorno de los niños. La distribución de los hogares en viviendas con tenencia de agua por cañería es uno de estos aspectos; al compararla en el tiempo, se observa que la mayoría de los departamentos conservan su posición relativa respecto al promedio nacional; sin embargo, también se observa una diferencia significativa en cuanto al número de departamentos que cambian de posición, siendo 6 de los 14 disponibles (véase cuadro 4). No obstante, los 8 departamentos que conservan su posición contienen cerca del 74 \% de la población del año 2013, indicando que el análisis de la distribución del año 2007 podría seguir teniendo validez para la mayoría de la población en esta categoría.

Cuadro 4. Distribución del porcentaje de las viviendas con tenencia de agua por cañería, 2007 versus 2013

\begin{tabular}{l|c|c|c|c|}
\hline \multirow{2}{*}{ Departamento } & \multicolumn{2}{c|}{ Valor } & \multicolumn{2}{c|}{ Posición } \\
\cline { 2 - 5 } & 2013 & 2007 & 2013 & 2007 \\
\hline Ahuachapán & 66.0 & 67.5 & Abajo del promedio & Arriba del promedio \\
Santa Ana & 70.4 & 63.4 & Abajo del promedio & Arriba del promedio \\
Sonsonate & 69.0 & 72.3 & Abajo del promedio & Arriba del promedio \\
Chalatenango & 86.7 & 61.0 & Arriba del promedio & Abajo del promedio \\
La Libertad & 81.5 & 72.0 & Arriba del promedio & Arriba del promedio \\
San Salvador & 88.9 & 82.6 & Arriba del promedio & Arriba del promedio \\
Cuscatlán & 79.7 & 67.1 & Arriba del promedio & Arriba del promedio \\
La Paz & 56.1 & 56.5 & Abajo del promedio & Abajo del promedio \\
Cabañas & 73.3 & 62.9 & Arriba del promedio & Arriba del promedio \\
San Vicente & 76.0 & 60.4 & Arriba del promedio & Abajo del promedio \\
Usulután & 63.1 & 52.3 & Abajo del promedio & Abajo del promedio \\
San Miguel & 71.5 & 58.6 & Abajo del promedio & Abajo del promedio \\
Morazán & 73.8 & 42.3 & Arriba del promedio & Abajo del promedio \\
La Unión & 57.4 & 51.9 & Abajo del promedio & Abajo del promedio \\
\hline
\end{tabular}

Fuente: EHPM 2007 y 2013. 
Una quinta variable para el análisis del entorno son los hogares en viviendas con abastecimiento de energía eléctrica. En este ítem 11 de los 14 departamentos mantienen su posición respecto al promedio del país, tal como lo muestra el cuadro 5.

Cuadro 5. Distribución del porcentaje de hogares en viviendas con abastecimiento de energía eléctrica, 2007 versus 2013

\begin{tabular}{l|c|c|c|c|}
\hline \multirow{2}{*}{ Departamento } & \multicolumn{2}{c|}{ Valor } & \multicolumn{2}{c|}{ Posición } \\
\cline { 2 - 5 } & 2013 & 2007 & 2013 & 2007 \\
\hline Ahuachapán & 85.8 & 79.6 & Abajo del promedio & Abajo del promedio \\
Santa Ana & 95.5 & 90.4 & Arriba del promedio & Arriba del promedio \\
Sonsonate & 91.0 & 91.0 & Abajo del promedio & Arriba del promedio \\
Chalatenango & 96.7 & 93.6 & Arriba del promedio & Arriba del promedio \\
La Libertad & 95.0 & 94.4 & Arriba del promedio & Arriba del promedio \\
San Salvador & 98.0 & 97.3 & Arriba del promedio & Arriba del promedio \\
Cuscatlán & 94.6 & 89.2 & Arriba del promedio & Arriba del promedio \\
La Paz & 94.3 & 91.6 & Arriba del promedio & Arriba del promedio \\
Cabañas & 97.1 & 82.8 & Arriba del promedio & Abajo del promedio \\
San Vicente & 94.7 & 91.7 & Arriba del promedio & Arriba del promedio \\
Usulután & 97.2 & 89.3 & Arriba del promedio & Arriba del promedio \\
San Miguel & 92.6 & 87.8 & Abajo del promedio & Arriba del promedio \\
Morazán & 93.1 & 59.9 & Abajo del promedio & Abajo del promedio \\
La Unión & 92.7 & 87.3 & Abajo del promedio & Abajo del promedio \\
\hline
\end{tabular}

Fuente: EHPM 2007 y 2013.

En el cuadro 6 se evidencia que en 13 departamentos se mantiene la posición relativa de los hogares en viviendas con piso de tierra respecto al promedio del país

Cuadro 6. Distribución del porcentaje de hogares en viviendas con piso de tierra, 2007 versus 2013

\begin{tabular}{l|c|c|c|c|}
\hline \multirow{2}{*}{ Departamento } & \multicolumn{3}{c|}{ Valor } & \multicolumn{2}{c|}{ Posición } \\
\cline { 2 - 5 } & 2013 & 2007 & 2013 & 2007 \\
\hline Ahuachapán & 40.7 & 34.0 & Arriba del promedio & Arriba del promedio \\
Santa Ana & 19.1 & 20.5 & Abajo del promedio & Abajo del promedio \\
Sonsonate & 25.1 & 24.2 & Arriba del promedio & Arriba del promedio \\
Chalatenango & 20.2 & 13.1 & Abajo del promedio & Abajo del promedio \\
La Libertad & 15.8 & 13.7 & Abajo del promedio & Abajo del promedio \\
San Salvador & 6.4 & 5.9 & Abajo del promedio & Abajo del promedio \\
Cuscatlán & 22.9 & 20.0 & Abajo del promedio & Abajo del promedio \\
La Paz & 21.8 & 17.5 & Abajo del promedio & Abajo del promedio \\
Cabañas & 23.2 & 27.2 & Abajo del promedio & Arriba del promedio \\
San Vicente & 19.0 & 19.1 & Abajo del promedio & Abajo del promedio \\
Usulután & 27.9 & 26.3 & Arriba del promedio & Arriba del promedio \\
San Miguel & 26.2 & 27.8 & Arriba del promedio & Arriba del promedio \\
Morazán & 37.3 & 50.7 & Arriba del promedio & Arriba del promedio \\
La Unión & 23.9 & 24.1 & Arriba del promedio & Arriba del promedio \\
\hline
\end{tabular}

Fuente: EHPM 2007 y 2013. 
Más contundentes son los resultados del cuadro 7, donde se muestra que la distribución de los hogares en viviendas con acceso a servicio sanitario, respecto al promedio del país, se mantiene invariante en ambos años.

Cuadro 7. Distribución del porcentaje de hogares en viviendas con acceso a servicio sanitario. 2007 versus 2013

\begin{tabular}{l|c|c|c|c|}
\hline \multirow{2}{*}{ Departamento } & \multicolumn{2}{|c|}{ Valor } & \multicolumn{2}{c|}{ Posición } \\
\cline { 2 - 5 } & 2013 & 2007 & 2013 & 2007 \\
\hline Ahuachapán & 96.8 & 90.0 & Arriba del promedio & Arriba del promedio \\
Santa Ana & 96.2 & 92.2 & Arriba del promedio & Arriba del promedio \\
Sonsonate & 96.7 & 91.7 & Arriba del promedio & Arriba del promedio \\
Chalatenango & 96.5 & 90.3 & Arriba del promedio & Arriba del promedio \\
La Libertad & 98.7 & 93.4 & Arriba del promedio & Arriba del promedio \\
San Salvador & 99.7 & 97.5 & Arriba del promedio & Arriba del promedio \\
Cuscatlán & 97.9 & 91.1 & Arriba del promedio & Arriba del promedio \\
La Paz & 97.4 & 90.7 & Arriba del promedio & Arriba del promedio \\
Cabañas & 89.4 & 83.1 & Abajo del promedio & Abajo del promedio \\
San Vicente & 96.7 & 90.4 & Arriba del promedio & Arriba del promedio \\
Usulután & 98.3 & 95.1 & Arriba del promedio & Arriba del promedio \\
San Miguel & 94.1 & 86.3 & Abajo del promedio & Abajo del promedio \\
Morazán & 91.2 & 67.9 & Abajo del promedio & Abajo del promedio \\
La Unión & 84.9 & 79.8 & Abajo del promedio & Abajo del promedio \\
\hline
\end{tabular}

Fuente: EHPM 2007 y 2013.

Por último, y no por eso menos importante, la distribución de las variables educativas, aproximadas por la Tasa de escolaridad promedio de la población de 6 años y más, evidencia que son 11 de los 14 departamentos del país los que mantienen su posición relativa respecto al promedio del país. (Véase cuadro 8.)

Cuadro 8. Distribución de la Tasa de Escolaridad promedio de la población de 6 años o más

\begin{tabular}{l|c|c|c|c|}
\hline \multirow{2}{*}{ Departamento } & \multicolumn{2}{c|}{ Valor } & \multicolumn{2}{c|}{ Posición } \\
\cline { 2 - 5 } & 2013 & 2007 & 2013 & 2007 \\
\hline Ahuachapán & 5.4 & 5.4 & Abajo del promedio & Arriba del promedio \\
Santa Ana & 6.0 & 5.7 & Arriba del promedio & Arriba del promedio \\
Sonsonate & 6.1 & 5.6 & Arriba del promedio & Arriba del promedio \\
Chalatenango & 5.8 & 5.1 & Abajo del promedio & Abajo del promedio \\
La Libertad & 6.9 & 6.3 & Arriba del promedio & Arriba del promedio \\
San Salvador & 8.2 & 7.4 & Arriba del promedio & Arriba del promedio \\
Cuscatlán & 6.1 & 5.3 & Arriba del promedio & Arriba del promedio \\
La Paz & 6.0 & 5.2 & Arriba del promedio & Abajo del promedio \\
Cabañas & 5.1 & 4.3 & Abajo del promedio & Abajo del promedio \\
San Vicente & 6.1 & 5.2 & Arriba del promedio & Abajo del promedio \\
Usulután & 5.9 & 5.0 & Abajo del promedio & Abajo del promedio \\
San Miguel & 6.1 & 5.4 & Arriba del promedio & Arriba del promedio \\
Morazán & 5.0 & 3.5 & Abajo del promedio & Abajo del promedio \\
La Unión & 4.7 & 4.1 & Abajo del promedio & Abajo del promedio \\
\hline
\end{tabular}

Fuente: EHPM 2007 y 2013. 


\section{Anexo 2. Territorios Funcionales de El Salvador}

\section{a. Territorios multi-municipales}

\begin{tabular}{|c|c|c|c|c|c|c|c|}
\hline \multirow[b]{2}{*}{ NÚMERO } & \multirow[b]{2}{*}{ COEFICIENTE } & \multicolumn{6}{|c|}{ NOMBRE } \\
\hline & & MUNICIPIO1 & MUNICIPIO2 & MUNICIPIO3 & MUNICIPIO4 & MUNICIPIO5 & MUNICIPIO6 \\
\hline & 0.7465055 & SAN SEBASTIÁN SALITRILLO & \begin{tabular}{|l} 
SANTA ANA \\
\end{tabular} & & & & \\
\hline 2 & 0.8728203 & SAN JUAN NONUALCO & ZACATECOLUCA & & & & \\
\hline 3 & 0.8770723 & EL REFUGIO & CHALCHUAPA & & & & \\
\hline 4 & 0.8971499 & SAN CAYETANO ISTEPEQUE & SAN VICENTE & & & & \\
\hline 5 & 0.8997234 & AHUACHAPÁN & TURÍN & & & & \\
\hline 6 & 0.9006788 & NUEVA GUADALUPE & QUELEPA & SAN MIGUEL & & & \\
\hline 7 & 0.9034510 & OLOCUILTA & SAN JUAN TALPA & SAN LUIS TALPA & & & \\
\hline 8 & 0.9040404 & GUACOTECTI & SENSUNTEPEQUE & & & & \\
\hline 9 & 0.9048387 & \begin{tabular}{|l|} 
JUAYÚA \\
\end{tabular} & SALCOATITÁN & & & & \\
\hline 10 & 0.9074074 & \begin{tabular}{|l|} 
ARCATAO \\
\end{tabular} & CHALATENANGO & SAN MIGUEL DE MERCEDES & & & \\
\hline 11 & 0.9090025 & COLÓN & SACACOYO & ARMENIA & & & \\
\hline 12 & 0.9099353 & NAHUILINGO & SAN ANTONIO DEL MONTE & SONSONATE & SONZACATE & & \\
\hline 13 & 0.9106153 & APOPA & GUAZAPA & & & & \\
\hline 14 & 0.9134944 & NUEVO CUSCATLÁN & SANTA TECLA & ZARAGOZA & SAN JOSÉ VILLANUEVA & & \\
\hline 15 & 0.9147287 & NOMBRE DE JESÚS & SAN ANTONIO DE LA CRUZ & & & & \\
\hline 16 & 0.9156438 & AGUILARES & \begin{tabular}{|l|} 
EL PAISNAL \\
\end{tabular} & & & & \\
\hline 17 & 0.9194114 & SAN BARTOLOMÉ PERULAPIAA & ILOPANGO & SOYAPANGO & SAN MARTÍN & & \\
\hline 18 & 0.9213360 & CIUDAD ARCE & COATEPEQUE & & & & \\
\hline 19 & 0.9227257 & JAYAQUE & \begin{tabular}{|l|} 
TALNIQUE \\
\end{tabular} & & & & \\
\hline 20 & 0.9239957 & JUCUAPA & SAN BUENAVENTURA & & & & \\
\hline 21 & 0.9243924 & SAN CARLOS & SAN FRANCISCO GOTERA & & & & \\
\hline 22 & 0.9255850 & OZATLÁN & SANTA MARÍA & USULUTÁN & & & \\
\hline 23 & 0.9303108 & EL ROSARIO & SANTIAGO NONUALCO & SAN RAFAEL OBRAJUELO & & & \\
\hline 24 & 0.9323155 & CONCHAGUA & LAUNIÓN & & & & \\
\hline 25 & 0.9338157 & COJUTEPEQUE & EL CARMEN & MONTE SAN JUAN & & & \\
\hline 26 & 0.9380435 & ANTIGUO CUSCATLÁN & AYUTUXTEPEQUE & SAN SALVADOR & SANTO TOMÁS & TONACATEPEQUE & SAN FRANCISCO CHINAMECA \\
\hline 27 & 0.9387050 & LA LIBERTAD & TAMANIQUE & & & & \\
\hline
\end{tabular}

Fuente: Amaya y Cabrera (2012).

b. Territorios uni-municipales

\begin{tabular}{|c|c|c|}
\hline Tho & DEPARTAMENTO & NOMBRE IF \\
\hline 28 & ARUAOCAPÁN & ApANECA \\
\hline 29 & AHUMOUPDiN & Anoveara \\
\hline 90 & AHUMOOAPAN & CONCEPCION DE ATACO \\
\hline 31 & ARUAOCUPÁN & GUanManco \\
\hline 32 & AHUAOCAPÁN & NuTH \\
\hline 33 & AruaOrapin & SWN FRANCSCO Menénde? \\
\hline 34 & AHUAOOADIN & SWN LOAENEO \\
\hline ss & AHUAOTAPAN & san pedeo puxtha \\
\hline 36 & AHUAOCADAN & Tacuea \\
\hline 37 & Casarias & Cincuera \\
\hline 38 & Caeatias & Doloees \\
\hline 99 & caeafias & ILCensco \\
\hline 40 & Caeafias & NTAPA \\
\hline 41 & Casarias & SAN ISORO \\
\hline 42 & CABARTAS & TEUTEPEQUE \\
\hline 43 & caeatios & Victorna \\
\hline 44 & CMALATENANGO & AGUA CaUENTE \\
\hline 45 & CMALATERANGO & AZACUALA \\
\hline 46 & CMULATENUNGO & cancasque \\
\hline 47 & chaLatenunco & cTalá \\
\hline 48 & CMALATERUNCO & COMNALAPA \\
\hline 49 & CMALATENUNCO & CONCEPCÓNN QUEZALTEPEQUE \\
\hline so & CMALATENUNGCO & DULCE NOMBRE DE MURia \\
\hline 51 & cruatenunco & EL CARRIZAL \\
\hline 52 & chauarenuvco & E pasaiso \\
\hline 53 & CHALATENUVVGo & L Laguna \\
\hline 54 & çULAтENUNCO & LAPALMA \\
\hline 55 & craLatenunco & LA Reina \\
\hline 56 & CHALATENUNCO & ushores \\
\hline 57 & CHALATENUNCO & us vutias \\
\hline 58 & chaLATENUNGo & NUEVA CONCEBCÓN \\
\hline 59 & CHaLATERUNCO & NUEVA TRINEDAO \\
\hline$\infty$ & CHALATERANCO & OJOS DE AGUA \\
\hline 61 & CHALATEUNGOO & POTONACO \\
\hline 62 & craLATENUNCo & SAN ANTTONHO LOS RANCHOS \\
\hline 63 & chaLatenunco & SAN FERALANDO \\
\hline 64 & chalatenunco & SAN FRANCASCO LeMEA \\
\hline 65 & chaLATERUNCo & SAN FRANCOSCO MORAZIN \\
\hline 66 & CHULATENUNGO & SWN IGMACOO \\
\hline 67 & CHALATERUNCO & SAN ISORO LABRADOR \\
\hline
\end{tabular}

\begin{tabular}{|c|c|c|}
\hline mo & DEPARTAMENTO & NOMBRE TF \\
\hline 68 & CMALATENANGO & SWN IUS Del Carmen \\
\hline 69 & CMNATENANGO & SAN Ratael. \\
\hline 70 & CHALATELANGO & SANTARTA \\
\hline$n$ & CHALTENUNGO & пยบนล \\
\hline $\boldsymbol{n}$ & cuscanin & canotuela \\
\hline 3 & cuscantín & El ROSARIO \\
\hline 74 & cuscanis & ORATOENO DE CONCEPOONN \\
\hline 75 & cuscandin & Sen CRstól \\
\hline 76 & cuscandin & SAN jost Guarasea \\
\hline$n$ & cuscatín & SLN PEDRO PERULARN \\
\hline 78 & Cuscanis & SLN RAFAEL CEDEOS \\
\hline$n$ & cuscanin & SeN RaMdN \\
\hline$\infty$ & cuscantin & SWVTA CRUZ avaLOUTO \\
\hline 81 & cuscandis & SWVTA CRUZ MEOWaA \\
\hline 82 & cuscantin & sucentoto \\
\hline 83 & cuscanín & tenunucanco \\
\hline 84 & L UEERTAD & Chllnupis \\
\hline as & LA Unektad & comasagua \\
\hline 86 & LA UEERTAD & mericas \\
\hline 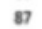 & LA UBERTAD & nccuon \\
\hline 8 & La ubektad & QuEzaltereque \\
\hline 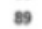 & LA UEestad & Sen Juav Onco \\
\hline 90 & LA UEERTAD & SaN matias \\
\hline 91 & LA UBektad & SAN PABLO TACAOACO \\
\hline 92 & La usektad & Teorepeout \\
\hline 93 & La UBERTAD & nencoro \\
\hline 94 & LAPA & cuncentis \\
\hline 95 & LAPAZ & terusaiten \\
\hline 96 & LAPNZ & Menctoes ua ctisa \\
\hline 97 & LAPN & PARuiso of OSOESO \\
\hline 98 & LAPAZ & SLN ANTONGO MaSentuAT \\
\hline 9 & LAPAZ & SAN EMEGDen \\
\hline 100 & LADNZ & SLN JUN TEPEZONTES \\
\hline 101 & LAPNZ & SAN LUS U RERSAOURA \\
\hline 102 & LAPNZ & SAN MEGUEL TELZONTIS \\
\hline 109 & LADE & SEN PEDEO MUSWHUAT \\
\hline 104 & $\angle A P Q Z$ & SLN PEDEO NONUALCO \\
\hline 105 & LAPNZ & sevta masia ostuma \\
\hline 106 & LADN & TAPAUTLECa \\
\hline 107 & La unadon & anumorós \\
\hline 100 & UA UnadN & Bouvar \\
\hline
\end{tabular}

\begin{tabular}{|c|c|c|}
\hline IFD & DEPARTAMENTO & NOMBRE TF \\
\hline 109 & LA UNIÓN & CONCEPCIÓN DE ORIENTE \\
\hline 110 & La Unáón & ACAEMEN \\
\hline$m$ & LAUNión & tesauce \\
\hline 112 & LA UNIÓN & innpucá \\
\hline 113 & LA UNIÓN & usuQve \\
\hline 114 & Launión & MEANGUERA DEL GOUFO \\
\hline 115 & La UNuón & NUEVA ESPARTA \\
\hline 116 & LA UNAÓN & PAsuavina \\
\hline 117 & LA UnIÓN & poconós \\
\hline 118 & La Uná́N & SANAEO \\
\hline 119 & La Unán & sanjost \\
\hline 120 & LA Uñón & SANTA ROSA DE UMAA \\
\hline 122 & LA UNIÓN & rayasmoue \\
\hline 122 & La UnNón & rucuarouin \\
\hline 123 & MORAZiN & ARAMEALA \\
\hline 124 & MOSNZiN & CACAOFERA \\
\hline 125 & MORUZiN & MLANGa \\
\hline 126 & Moruzin & Cosivito \\
\hline 127 & MOQAZZiN & DEUCAS DE CONCEDOÓN \\
\hline 128 & MORaLiN & EL ONISLERRO \\
\hline 129 & Morazin & thosanio \\
\hline 130 & MORNZiN & GUALOCOCN \\
\hline 131 & MORAZiN & guatalagua \\
\hline 132 & MORAZZiN & JOATECA \\
\hline 133 & MORAZiN & jocoannaue \\
\hline 134 & MORAZLiN & 10CORO \\
\hline 135 & Moruzin & Lotonoumuo \\
\hline 136 & Mosuzin & MEANGUERA \\
\hline 137 & MORAZiN & osicala \\
\hline 138 & MORAZiN & PERQUíN \\
\hline 139 & MORUZiN & SAN FERUANDO \\
\hline 140 & Moruzin & SAN ISIORO \\
\hline 141 & MOQAZEN & SAN SEMÓN \\
\hline 142 & MORuziN & sensemeata \\
\hline 143 & MORuZiN & SOCIEDAD \\
\hline 144 & MORAZiN & TOROA \\
\hline 145 & MORAZZiN & rameaseal \\
\hline 146 & Morazin & rolowouin \\
\hline 147 & SAN MUGUEL & CAROUMA \\
\hline 148 & SAN MIGUEL & OHaptinove \\
\hline 149 & SAN MIGUEL & OANAMECA \\
\hline
\end{tabular}




\begin{tabular}{|c|c|c|c|c|}
\hline mio & DEPARTAMENTO & NOMBRE IF & DEPARTANENTO & NOMBRE TF \\
\hline & & & 191 SANTA ANA & TEXESTEPEQUE \\
\hline 150 & SAN MACUEL & OMinugua & 192 SONSONATE & ACAUUTLA \\
\hline 251 & SAN MGGUEL & CuOAd Bactios & 193 SONSONATE & caluco \\
\hline 152 & SAN MAGUEL & comacualin & 194 SONSONATE & CUISNAHUAT \\
\hline 153 & SAN MEGUEL & A trivsto & 195 SONSONATE & IZALCO \\
\hline 154 & SAN MAGUEL & Lotonout & 196 SONSONATE & NAHUIZALCO \\
\hline 25s & SAN MAGUEL & Moncugua & 197 SONSONATE & SAN JUUAN \\
\hline 156 & SAN MECUEL & NUEVO EDÉN DE SUN IUAN & 198 SONSONATE & SANTA CATAFUNA MUSAHUA \\
\hline 257 & San Macuel & SAN ANTOWab & 199 SONSONATE & SANTA ISABER ISHUATÁN \\
\hline 150 & SAN MacutL & SAN Gerakdo & 200 SONSONATE & SANTO DOMINGO DE GUEN \\
\hline 159 & SAN MEGUEL & san joect & 201 USULUTAN & ALEGRIA \\
\hline 160 & SAN MECUEL & SWN turs of L A Reina & 202 USUUUTAN & BERLIN \\
\hline 261 & SAN MEGUEL & SWN BAFAEL OEIENTE & 203 USUUUTAN & CAUFORNIA \\
\hline 162 & SAN MEGUEL & sesom & 204 USUUTTÁN & CONCEPCION BATRES \\
\hline 163 & SaN MeGUel & vivazapa & 205 USULUTAN & E. TREUNFO \\
\hline 164 & SAN Salvadoo & OUDRD Detcado & 206 USUUUTAN & EREGUAYQUIN \\
\hline 265 & SAN SWIVADOA & Cuscatancinco & 207 USULUTÁN & ESTANZuELAS \\
\hline 166 & SAN SALVADOA & Mtucanos & 208 USULUTÁN & JlQuiusco \\
\hline 167 & SAN SALVADOA & newan & 209 USULUTÁN & JUCUARÉN \\
\hline 260 & SAN SaLVADOA & PANCOAMULCO & 210 USUUUTÁN & MERCEDES UMANNA \\
\hline 160 & SaN SWivadou & nosuves of Mosen & 211 USUUUTÁN & NUEVA GRANADA \\
\hline 170 & SAN SWIVADOA & saw muacos & 212 USUUUTÁN & PUERTO EL TRIUNFO \\
\hline in & SAN SalvADOR & suvmuco trecuavess & 213 USULUTÁN & SAN AGUSTIN \\
\hline $1 n$ & San vicentt & asastrveque & 2144 USUUUTÁN & SAN DIONISIO \\
\hline 273 & SAN VCENTE & Guaduave & 215 USUUUTÁN & SAN FRANCISCO JAVIER \\
\hline 174 & SAN Vuctente & SAN ESTESAN CaTakana & 216 USUUUTÁN & SANTA ELENA \\
\hline 175 & SAN VICENTE & sav soeronso & 217 USUUUTÁN & SANTLAGO DE MARÍA \\
\hline 176 & SAN vicente & swivioneso & 218 USUUUTAN & TECADAN \\
\hline in & SAN VICENTE & Sav seteustin & & \\
\hline 178 & SAN vicente & suvtacies & & \\
\hline 179 & SAN VICENTE & SANTO dOAMUVO & & \\
\hline 180 & San valete & recouca & & \\
\hline 281 & SAN VICENTE & TEsentin & & \\
\hline 182 & SAN VICENTE & verowe & & \\
\hline 183 & SANTA aNe & CANOELARLA DE LA FRONTERA & & \\
\hline 184 & Savta are & El CONGSO & & \\
\hline 185 & SANTA AOUA & A PContener & & \\
\hline 186 & SANTA aNe & moservat & & \\
\hline 187 & SANTA ANA & MetapiN & & \\
\hline 18 & SANTA aOU & SAN ANTOWHO PANOWLAC & & \\
\hline 189 & SANTA AOUA & SANTA Rosa GuaOMIRLiN & & \\
\hline 190 & SANTA ave & SANTHGO DE UA FRONTERA & & \\
\hline
\end{tabular}

Fuente: Amaya y Cabrera (2012). 
Anexo 3. Cobertura y Distancia en el IOH en Acceso al Agua
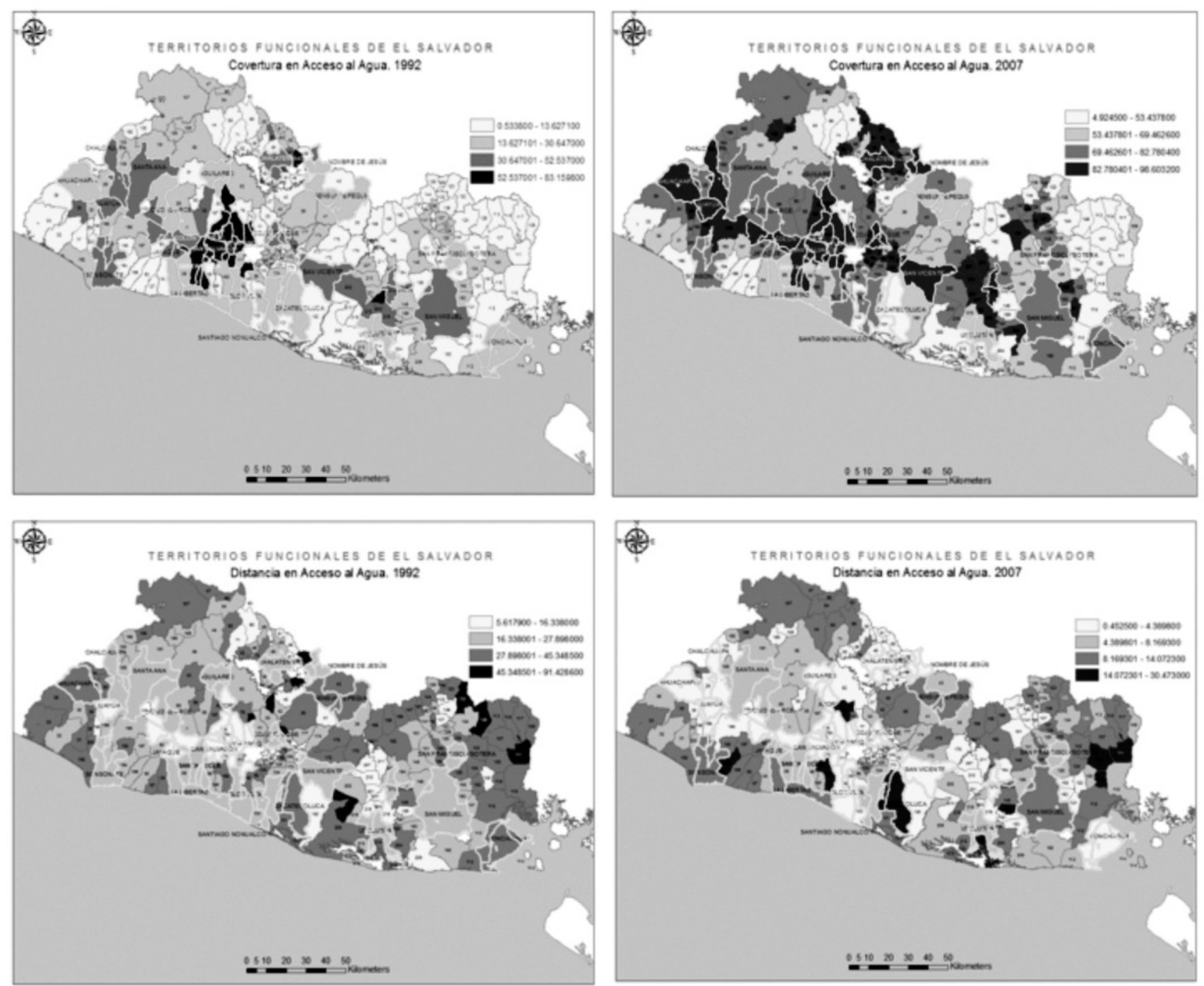

Fuente: Elaboración propia con base en IV Censos de Población y III de Vivienda de El Salvador del año 1992 y de los V Censos de Población y IV de Vivienda de El Salvador del año 2007. 


\section{Anexo 4. Cobertura y Distancia en el IOH en Saneamiento}
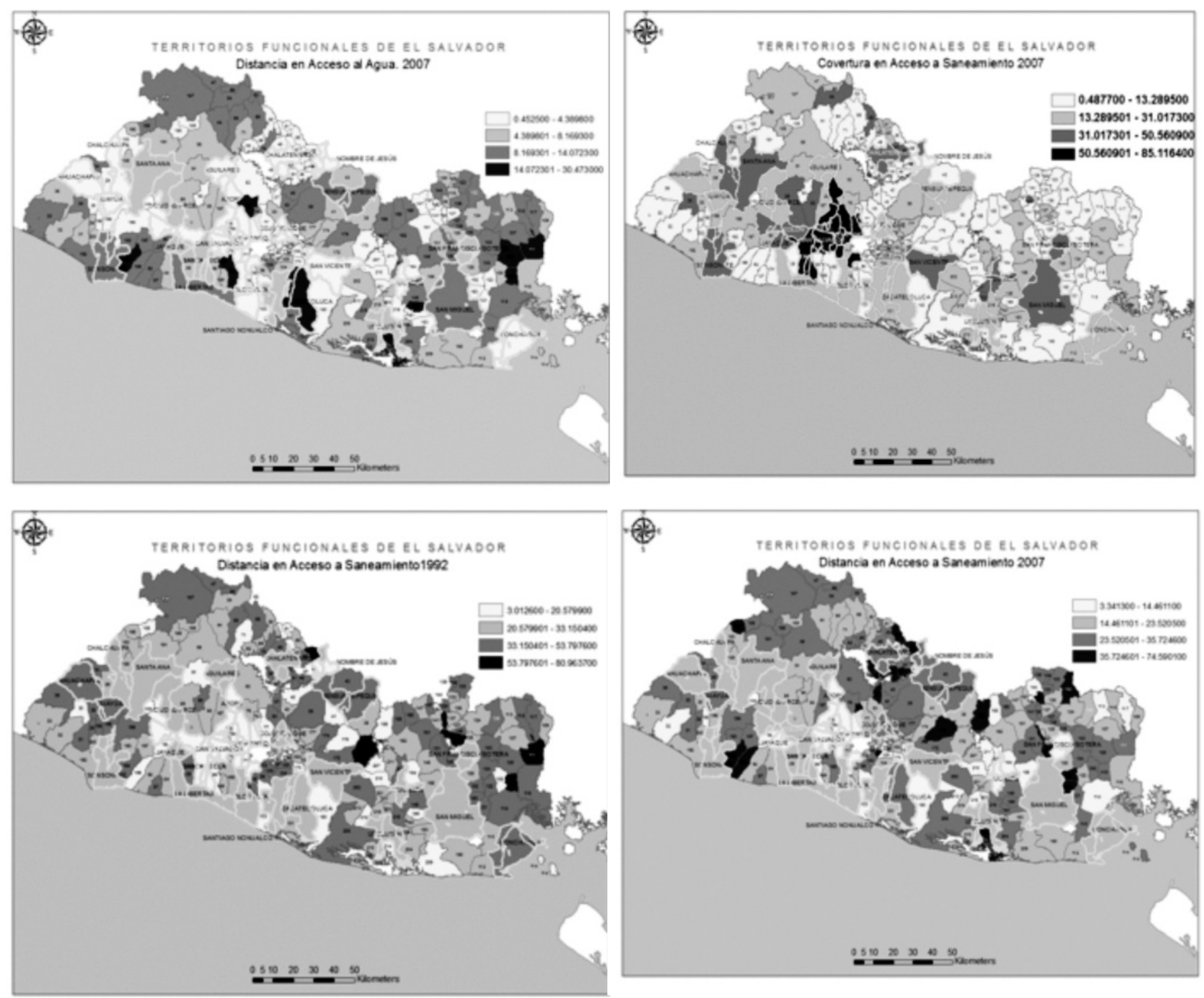

Fuente: Elaboración propia con base en IV Censos de Población y III de Vivienda de El Salvador del año 1992 y de los V Censos de Población y IV de Vivienda de El Salvador del año 2007. 
Anexo 5. Cobertura y Distancia en el IOH en Asistencia a la Escuela
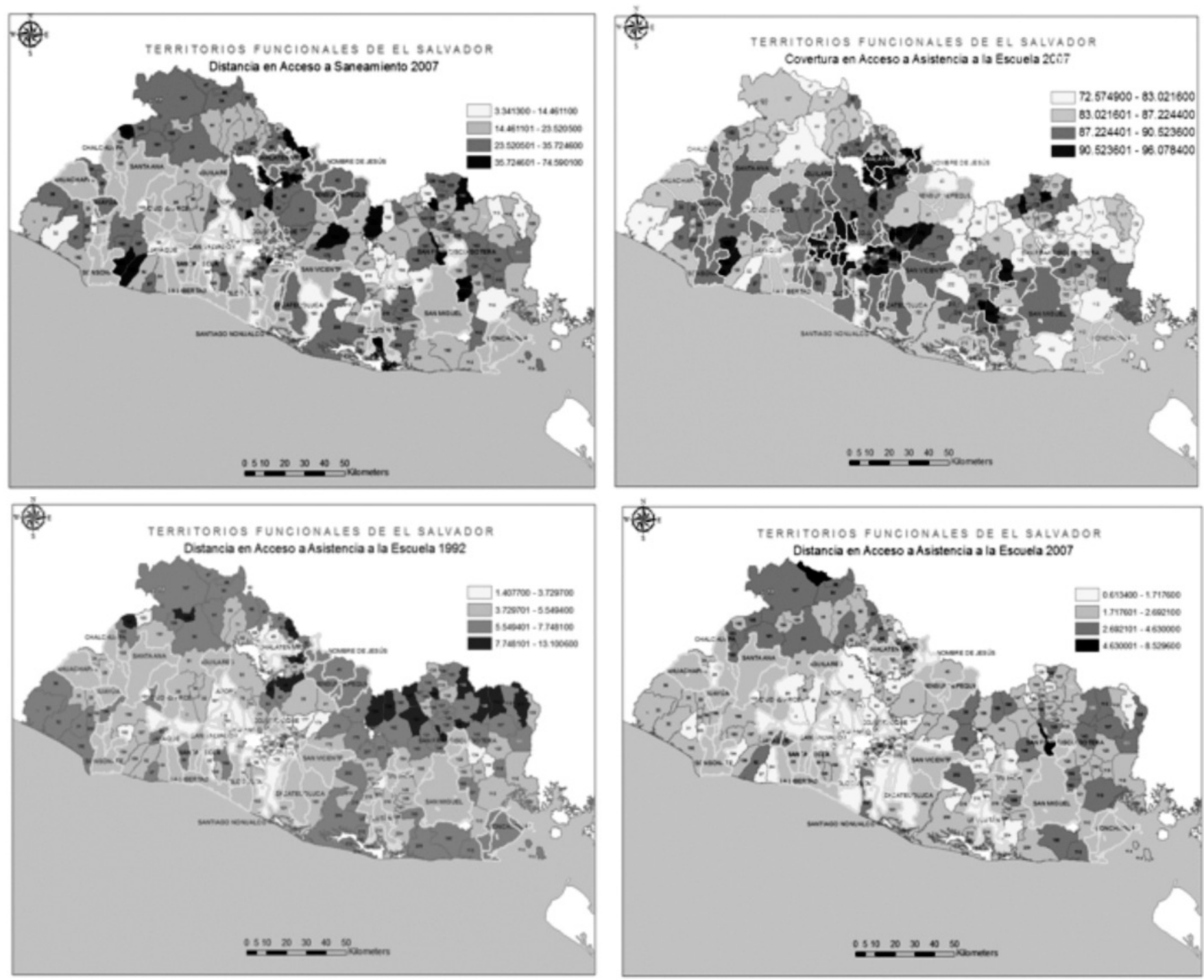

Fuente: Elaboración propia con base en IV Censos de Población y III de Vivienda de El Salvador del año 1992 y de los V Censos de Población y IV de Vivienda de El Salvador del año 2007. 


\section{Anexo 6. Cobertura y Distancia en el IOH en Escolaridad a Tiempo}
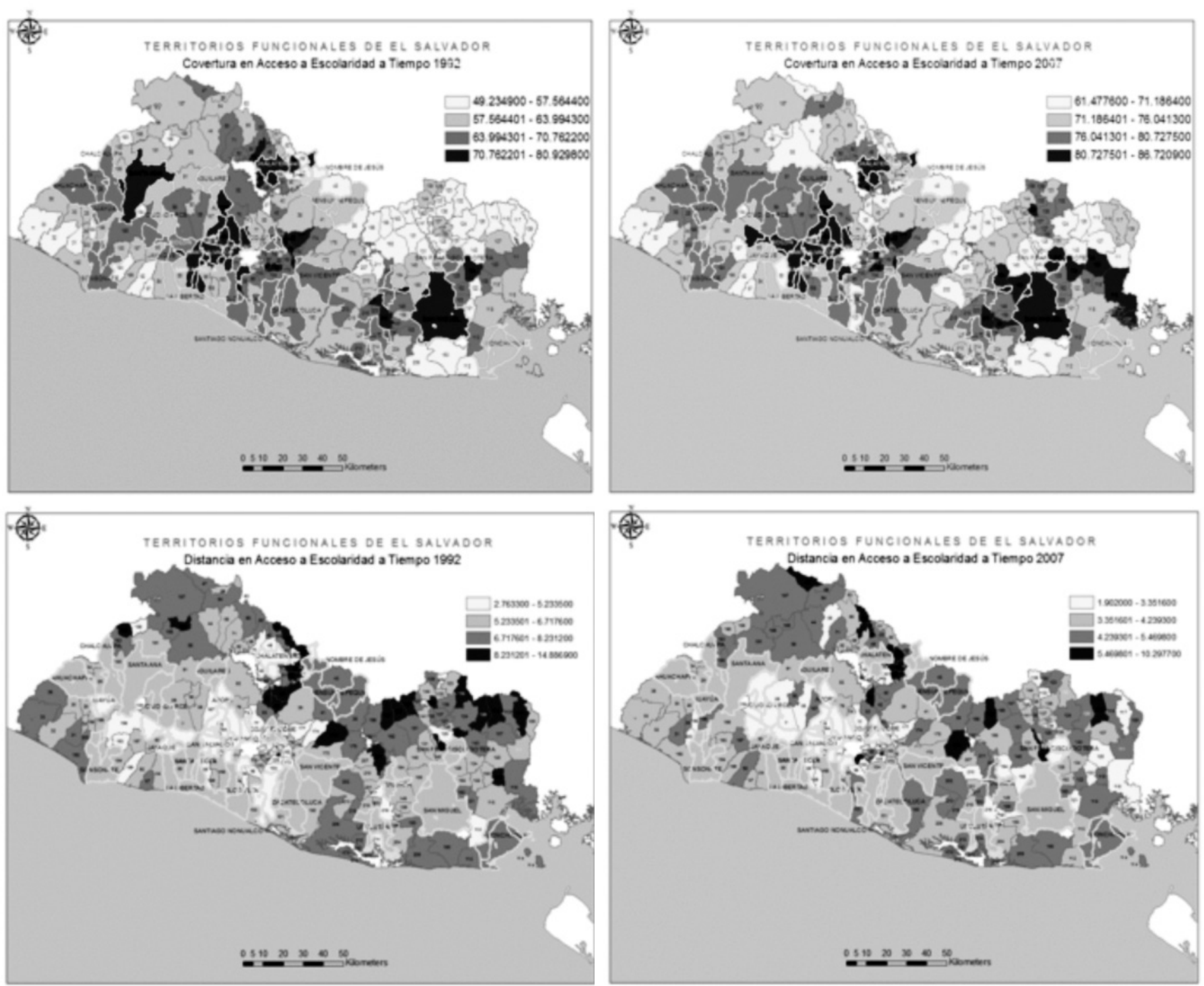

Fuente: Elaboración propia con base en IV Censos de Población y III de Vivienda de El Salvador del año 1992 y de los V Censos de Población y IV de Vivienda de El Salvador del año 2007. 


\section{Anexo 7. Cobertura y Distancia en el IOH en Acceso a Refrigerador, Teléfono y Electricidad}
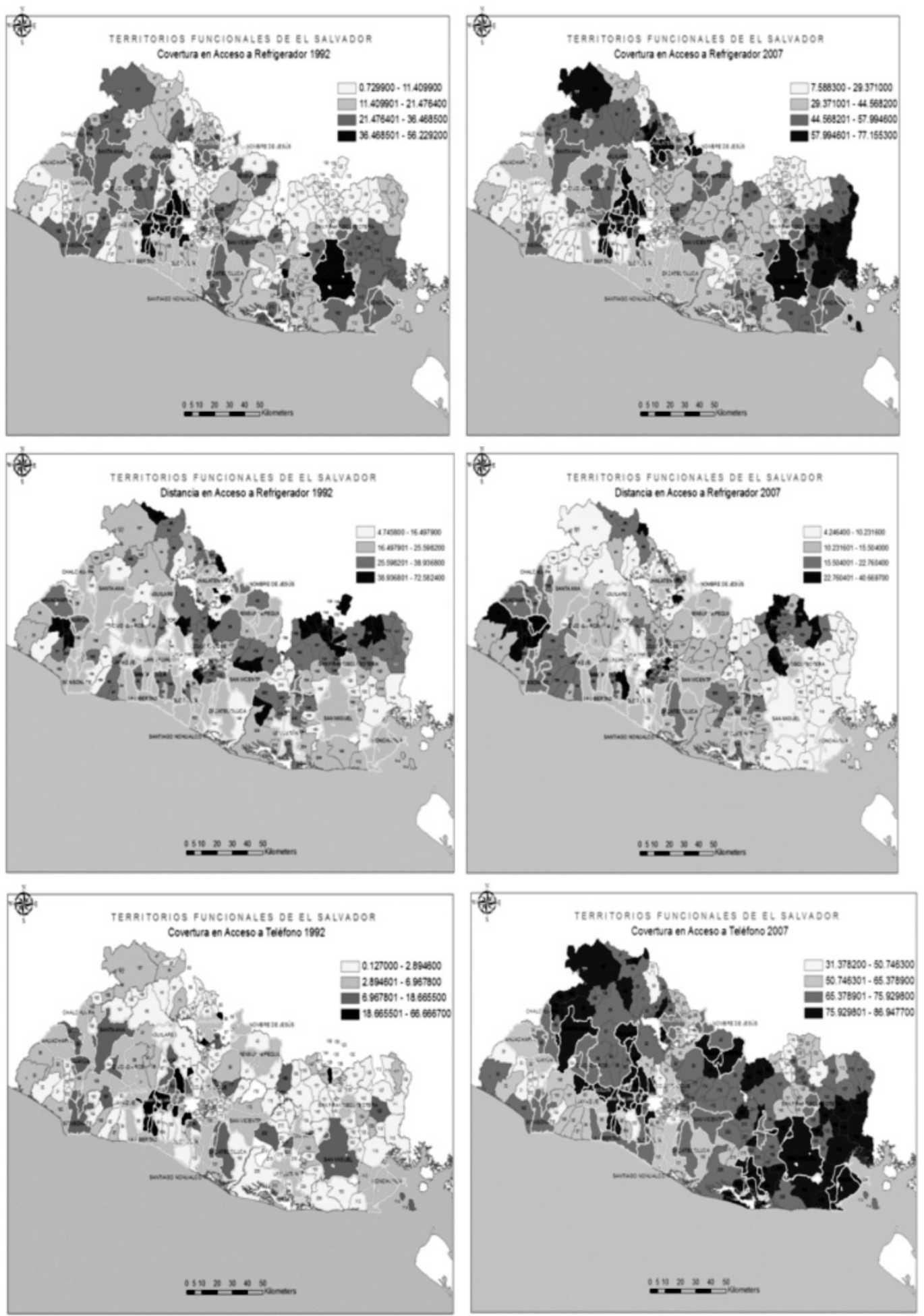

Fuente: Elaboración propia con base en IV Censos de Población y III de Vivienda de El Salvador del año 1992 y de los V Censos de Población y IV de Vivienda de El Salvador del año 2007. 

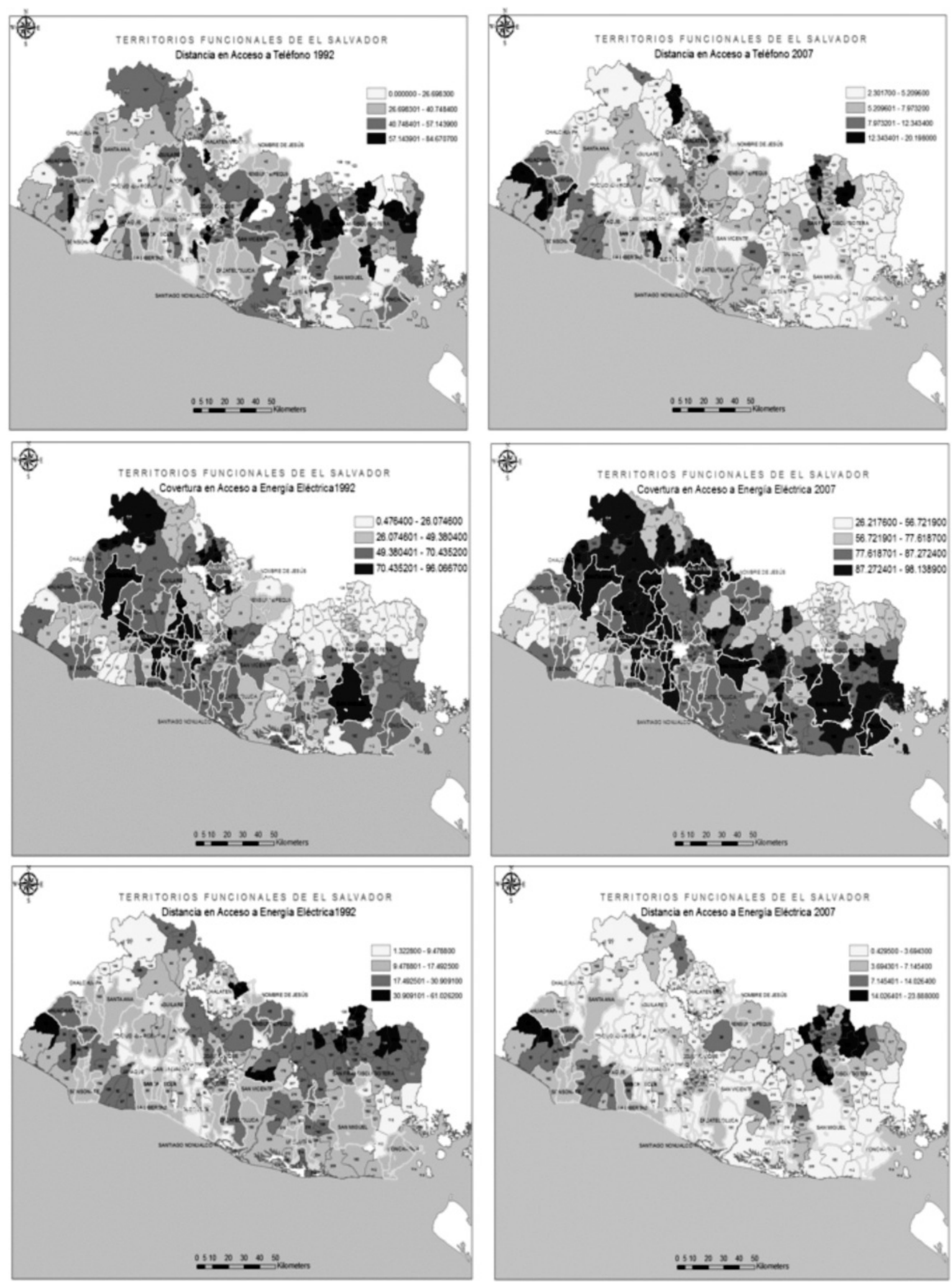
Anexo 8. Cobertura y Distancia en el IOH en Acceso a Materialidad de la Vivienda y Hogar no Hacinado
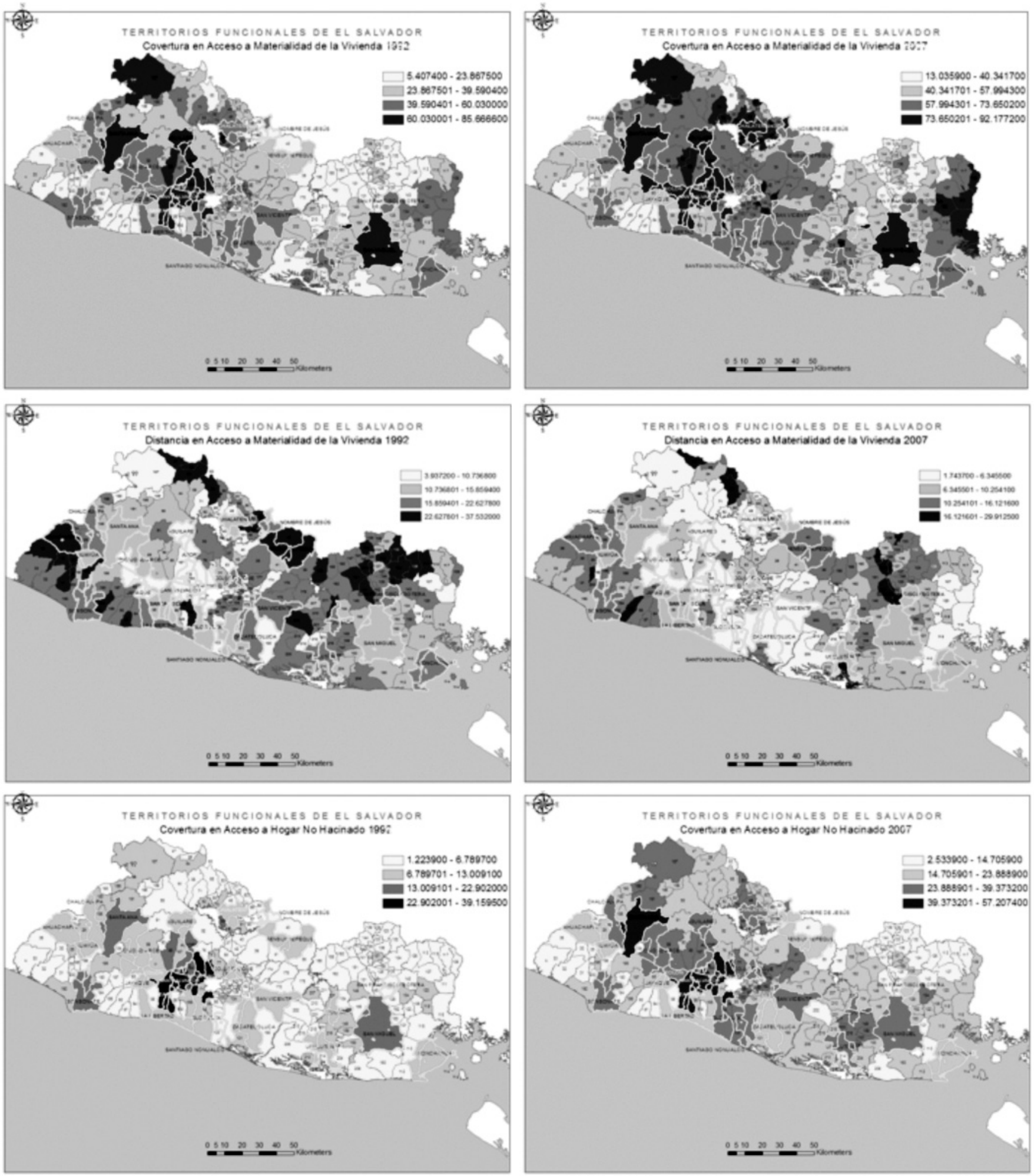

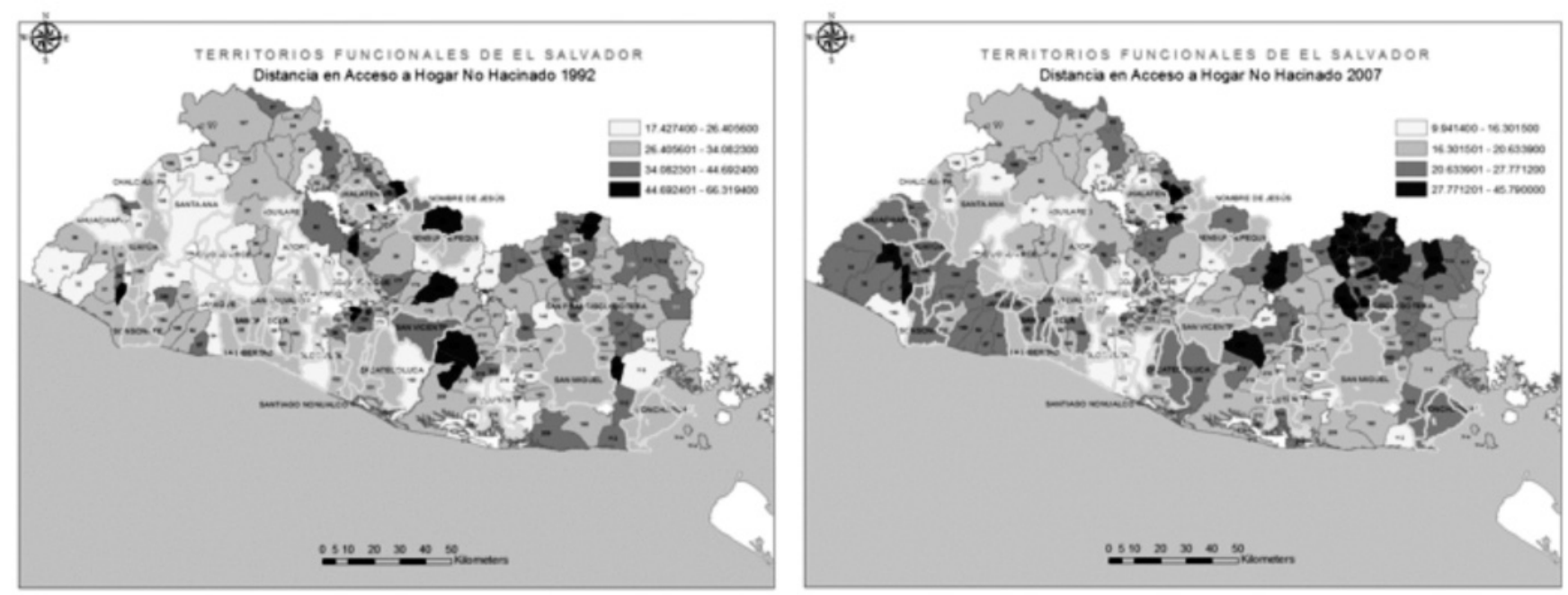

Fuente: Elaboración propia con base en IV Censos de Población y III de Vivienda de El Salvador del año 1992 y de los V Censos de Población y IV de Vivienda de El Salvador del año 2007. 